\title{
Corporate Bond Liquidity Before and After the Onset of the Subprime Crisis
}

Dick-Nielsen, Jens; Feldhütter, Peter; Lando, David

\author{
Document Version \\ Final published version \\ Published in: \\ Journal of Financial Economics \\ DOI: \\ 10.1016/j.jfineco.2011.10.009 \\ Publication date: \\ 2012 \\ License \\ CC BY-NC-ND
}

Citation for published version (APA):

Dick-Nielsen, J., Feldhütter, P., \& Lando, D. (2012). Corporate Bond Liquidity Before and After the Onset of the Subprime Crisis. Journal of Financial Economics, 103(3), 471-492. https://doi.org/10.1016/j.jfineco.2011.10.009

Link to publication in CBS Research Portal

\section{General rights}

Copyright and moral rights for the publications made accessible in the public portal are retained by the authors and/or other copyright owners and it is a condition of accessing publications that users recognise and abide by the legal requirements associated with these rights.

\section{Take down policy}

If you believe that this document breaches copyright please contact us (research.lib@cbs.dk) providing details, and we will remove access to the work immediately and investigate your claim.

Download date: 26. Apr. 2023
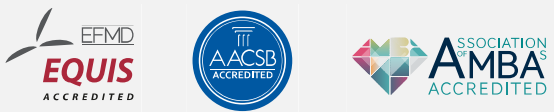


\title{
Corporate bond liquidity before and after the onset of the subprime crisis ${ }^{2 / 2}$
}

\author{
Jens Dick-Nielsen ${ }^{\mathrm{a}}$, Peter Feldhütter ${ }^{\mathrm{b}}$, David Lando ${ }^{\mathrm{a}, *}$ \\ a Department of Finance, Copenhagen Business School, Solbjerg Plads 3, DK-2000 Frederiksberg, Denmark \\ ${ }^{\mathrm{b}}$ London Business School, Regent's Park, London NW1 4SA, United Kingdom
}

\section{A R T I C L E I N F O}

\section{Article history:}

Received 6 July 2010

Received in revised form

9 May 2011

Accepted 28 May 2011

Available online 3 November 2011

\section{JEL classification:}

C23

G01

G12

\section{Keywords:}

Corporate bonds

Liquidity

Liquidity risk

Subprime crisis

\begin{abstract}
A B S T R A C T
We analyze liquidity components of corporate bond spreads during 2005-2009 using a new robust illiquidity measure. The spread contribution from illiquidity increases dramatically with the onset of the subprime crisis. The increase is slow and persistent for investment grade bonds while the effect is stronger but more short-lived for speculative grade bonds. Bonds become less liquid when financial distress hits a lead underwriter and the liquidity of bonds issued by financial firms dries up under crises. During the subprime crisis, flight-to-quality is confined to AAA-rated bonds.
\end{abstract}

(c) 2011 Elsevier B.V. All rights reserved.

\section{Introduction}

The onset of the subprime crisis caused a dramatic widening of corporate bond spreads. In light of the strong

\footnotetext{
We thank Yakov Amihud, Sreedhar Bharath, Jeff Bohn, Michael Brennan, Tom Engsted, Edie Hotchkiss, Loriano Mancini, Marco Pagano, Lasse Pedersen, Ilya Strebulaev and participants at seminars at the Goethe University in Frankfurt, Danmarks Nationalbank, Deutsche Bundesbank, ECB, AQR Asset Management, Moody's Investors Service, Oesterreichische Nationalbank, CBS, NYU, PenSam, VU University Amsterdam, USI Lugano, and at conferences in Bergen (EFA), Konstanz, Florence, London (Moody's 7th Credit Risk Conference 2011), EPFL Lausanne, and Venice for helpful comments. Peter Feldhütter thanks the Danish Social Science Research Council for financial support. We are especially indebted to the referee Edith Hotchkiss for many valuable suggestions.

* Corresponding author

E-mail addresses: jdn.fi@cbs.dk (J. Dick-Nielsen), pfeldhutter@london.edu (P. Feldhütter), dl.fi@cbs.dk (D. Lando).
}

evidence that illiquidity in addition to credit risk contributes to corporate bond spreads, it is reasonable to believe that at least part of the spread-widening can be attributed to a decrease in bond liquidity. We use TRACE (Trade Reporting and Compliance Engine) transactions data for corporate bonds and a new measure of liquidity to analyze how illiquidity has contributed to bond spreads before and after the onset of the subprime crisis. Our liquidity measure outperforms the Roll (1984) measure used in Bao, Pan, and Wang (2011) and zero-trading days used in Chen, Lesmond, and Wei (2007) in explaining spread variation.

We use the measure to define the liquidity component of bond spreads as the difference in bond yields between a bond with average liquidity and a very liquid bond. At the onset of the crisis, the liquidity component rose for all rating classes except AAA. The increase occurred both because of falling bond liquidity and because of increased sensitivity of bond spreads to illiquidity. Before the crisis 
the liquidity component was small for investment grade, ranging from 1 basis point (bp) for AAA to $4 \mathrm{bp}$ for BBB. For AAA bonds the contribution remained small at 5bp during the crisis-consistent with a flight-to-quality into those bonds. More dramatically, the liquidity component for BBB bonds increased to 93bp, and for speculative grade bonds rose from 58 to $197 \mathrm{bp}$. For speculative grade bonds, premiums peaked around the Lehman Brothers default in the fall of 2008 and returned almost to pre-crisis levels in the summer of 2009.

We also use our measure to provide suggestive evidence of the mechanisms by which bond liquidity was affected. If lead underwriters are providers of liquidity of a bond in secondary market trading, it is conceivable that financial distress of a lead underwriter causes the liquidity of the bond to decrease relative to other bonds. We find that bonds which had Bear Stearns as lead underwriter had lower liquidity during the take-over of Bear Stearns and bonds with Lehman as lead underwriter had lower liquidity around the bankruptcy of Lehman. Furthermore, we investigate whether the time-series variation of liquidity of corporate bonds issued by financial firms is different from the variation for bonds issued by industrial firms. Our timeseries study reveals that bonds issued by financial firms had similar liquidity as bonds issued by industrial firms, except in extreme stress periods, where bonds of financial firms became very illiquid, overall and when compared to bonds issued by industrial firms. A potential explanation is the heightened information asymmetry regarding the state of financial firms.

Finally, measuring the covariation of an individual bond's liquidity with that of the entire corporate bond market, we find that this measure of systematic liquidity risk was not a significant contributor to spreads before the onset of the crisis but did contribute to spreads after the onset except for AAA-rated bonds. This indicates that the flight-to-quality effect in investment grade bonds found in Acharya, Amihud, and Bharath (2010) is confined to AAA-rated bonds.

Our liquidity measure, which we denote $\lambda$, is an equally weighted sum of four variables all normalized to a common scale: Amihud's measure of price impact, a measure of roundtrip cost of trading, and the variability of each of these two measures. We can think of the Amihud measure and the roundtrip cost measure as measuring liquidity, and the variability measures as representing the sum of systematic and unsystematic liquidity risk. Due to the infrequent trading of bonds, we find it difficult to measure the systematic part accurately on a frequent basis, so we use total liquidity risk and study the systematic part separately. $\lambda$ is a close approximation to the first principal component extracted among a large number of potential liquidity proxies. When we regress corporate bond spreads on $\lambda$ and control for credit risk, the measure contributes to spreads consistently across ratings and in our two regimes. This consistency is important for drawing conclusions when we split the sample by industry and lead underwriter. The TRACE transactions data allow us to calculate liquidity proxies more accurately and help us shed new light on previous results on liquidity in corporate bonds. Once actual transactions data are used, the finding in Chen, Lesmond, and Wei (2007) that zero-trading days predict spreads largely disappears. In fact, the number of zero-trading days tends to decrease during the crisis, because trades in less liquid bonds are split into trades of smaller size.

We perform a series of robustness checks, and the two most important checks are as follows. To support the claim that our measure $\lambda$ is not measuring credit risk, we run regressions on a matched sample of corporate bonds using pairs of bonds issued by the same firm with maturity close to each other. Instead of credit controls, we use a dummy variable for each matched pair and estimate how spreads depend on $\lambda$. In this alternative approach to controlling for credit risk, $\lambda$ consistently remains significant. The second check relates to the fact that we use data for bonds for which we have transactions for some period during 20052009. To test that our results are not confounded by an increase in new issues towards the end of the sample period, we redo results using only bonds in existence by 2005, and results remain similar.

The literature on how liquidity affects asset prices is extensive. A comprehensive survey can be found in Amihud, Mendelson, and Pedersen (2005). In recent years, the illiquidity of corporate bonds has been seen as a possible explanation for the 'credit spread puzzle,' i.e., the claim that yield spreads on corporate bonds are larger than what can be explained by default risk (see Huang and Huang, 2003; Elton, Gruber, Agrawal, and Mann, 2001; Collin-Dufresne, Goldstein, and Martin, 2001). Earlier papers showing that liquidity proxies are significant explanatory variables for credit spreads are Houweling, Mentink, and Vorst (2005), Downing, Underwood, and Xing (2005), de Jong and Driessen (2006), Sarig and Warga (1989), and Covitz and Downing (2007). Lin, Wang, and Wu (2011) study liquidity risk in the corporate bond market but do not focus on the regime-dependent nature of liquidity risk. Bao, Pan, and Wang (2011) extract an aggregate liquidity measure from investment grade bonds using the Roll measure and examine the pricing implications of illiquidity. The fact that $\lambda$ is more robust than the Roll measure allows us to get a more detailed picture of bond market liquidity across underwriter, sector, and rating. Furthermore, we investigate the liquidity of both investment grade and speculative grade bonds.

\section{Data description}

Since January 2001, members of the Financial Industry Regulatory Authority have been required to report their secondary over-the-counter corporate bond transactions through TRACE (Trade Reporting and Compliance Engine). Because of the uncertain benefit to investors of price transparency, not all trades reported to TRACE were initially disseminated at the launch of TRACE on July 1 , 2002. Since October 2004, trades in almost all bonds except some lightly traded bonds are disseminated (see Goldstein and Hotchkiss, 2008, for details). Because we use quarterly observations, we start our sample period at the beginning of the subsequent quarter.

We use a sample of corporate bonds which have some trade reports in TRACE during the period January 1, 2005 to June 30,2009 . We limit the sample to fixed rate bullet bonds that are not callable, convertible, putable, or have 
sinking fund provisions. We obtain bond information from Bloomberg, and this provides us initially with 10,785 bond issues. We use ratings from Datastream and bonds with missing ratings are excluded. ${ }^{1}$ This reduces the sample to 5,376 bonds. Retail-sized trades (trades below $\$ 100,000$ in volume) are discarded and after filtering out erroneous trades, as described in Dick-Nielsen (2009), we are left with $8,212,990$ trades. Finally, we collect analysts' forecast dispersion from IBES, share prices for the issuing firms and firm accounting figures from Bloomberg, swap rates from Datastream, Treasury yields consisting of the most recently auctioned issues adjusted to constant maturities published by the Federal Reserve in the $\mathrm{H}-15$ release, and LIBOR rates from British Bankers' Association. If forecast dispersion, share prices, or firm accounting figures are not available, we drop the corresponding observations from the sample.

\section{Empirical methodology}

This section provides details on the regression analysis conducted in the next section and defines the set of liquidity variables we use.

\subsection{Regression}

As dependent variable we use the yield spread to the swap rate for every bond at the end of each quarter. Implementation details are given in Appendix A.

To control for credit risk, we follow Blume, Lim, and MacKinlay (1998) and add the ratio of operating income to sales, ratio of long term debt to assets, leverage ratio, equity volatility, and four pretax interest coverage dummies to the regressions. ${ }^{2}$ To capture effects of the general economic environment on the credit risk of firms, we include the level and slope of the swap curve, defined as the 10-year swap rate and the difference between the 10-year and 1-year swap rate. Duffie and Lando (2001) show that credit spreads may increase when there is incomplete information on the firm's true credit quality. To proxy for this effect, we follow Güntay and Hackbarth (2010) and use dispersion in earnings forecasts as a measure of incomplete information. Finally, we add bond age, timeto-maturity, and size of coupon to the regressions; see, for example, Sarig and Warga (1989), Houweling, Mentink, and Vorst (2005), and Longstaff, Mithal, and Neis (2005). We do not use Credit Default Swap (CDS) data since that would

\footnotetext{
${ }^{1}$ We use the rating from Standard and Poor's. If this rating is missing, we use the rating from Moody's and if this is missing, the rating from Fitch. If we still do not have a rating we use the company rating.

2 The pretax interest coverage dummies are defined as follows. We define the pretax interest rate coverage (IRC) ratio as EBIT divided by interest expenses. It expresses how easily the company can cover its interest rate expenses. However, the distribution is highly skewed. As in Blume, Lim, and MacKinlay (1998), we control for this skewness by creating four dummies (pretax dummies) which allows for a non-linear relationship with the spread. The first dummy is set to the IRC ratio if it is less than 5 and 5 if it is above. The second dummy is set to zero if IRC is below 5 , to the IRC ratio minus 5 if it lies between 5 and 10 , and 5 if it lies above. The third dummy is set to zero if IRC is below 10, to the IRC ratio minus 10 if it lies between 10 and 20, and 10 if it lies above. The fourth dummy is set to zero if IRC is below 20 and is set to IRC minus 20 if it lies above 20 (truncating the dummy value at 80 ).
}

restrict the sample to only those firms for which CDS contracts are trading.

For each rating class, we run separate regressions using quarterly observations. The regressions are

$$
\begin{aligned}
\text { Spread }_{i t}= & \alpha+\gamma \text { Liquidity }_{i t}+\beta_{1} \text { Bond age }_{i t} \\
& +\beta_{2} \text { Amount issued }_{i t}+\beta_{3} \text { Coupon }_{i t} \\
& +\beta_{4} \text { Time-to-maturity }_{i t}+\beta_{5} \text { Eq. }_{i t} \\
& +\beta_{6} \text { Operating }_{i t}+\beta_{7} \text { Leverage }_{i t}+\beta_{8} \text { Long debt }_{i t} \\
& +\beta_{9, \text { pretax }} \text { Pretax dummies }_{i t}+\beta_{10} 10 \mathrm{y} \text { Swap }_{t} \\
& +\beta_{11} 10 \mathrm{y}-1 \mathrm{y} \text { Swap }_{t} \\
& +\beta_{12} \text { Forecast dispersion }_{i t}+\epsilon_{i t},
\end{aligned}
$$

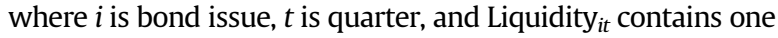
of the liquidity proxies defined below. Since we have panel data of yield spreads with each issuer potentially having more than one bond outstanding at any point in time, we calculate two-dimensional cluster robust standard errors (see Petersen, 2009). This corrects for time-series effects, firm fixed effects, and heteroskedasticity in the residuals.

\subsection{Liquidity measures}

There is no consensus on how to measure the liquidity of an asset so we examine a number of liquidity-related measures for corporate bonds. Appendix A describes the measures and their implementation in more detail.

We use the Amihud (2002) illiquidity measure to estimate the price impact of trades, defined as the price impact of a trade per unit traded. We proxy for bid-ask spreads using two different measures, the Roll measure and Imputed Roundtrip Trades. Roll (1984) finds that under certain assumptions, the bid-ask spread can be extracted from the covariance between consecutive returns, and the Roll measure is based on this insight. Feldhütter (in press) proposes to measure bid-ask spreads using Imputed Roundtrip Trades (IRT). Most of the data do not contain information about the buy and sell side in trades, and IRTs are based on finding two trades close in time that are likely to be a buy and a sell. Such trades are used to construct Imputed Roundtrip Costs, IRC, as explained in Appendix A.

We also consider trading activity measures. Turnover is the quarterly turnover in percent of total amount outstanding, while zero-trading days measures the percentage of days during a quarter where a bond does not trade. We also calculate firm zero-trading days as the percentage of days during a quarter where none of the issuing firm's bonds traded. Even if a single bond seldom trades, the issuing firm might have many bonds outstanding and there might be frequent trading in these close substitutes.

Finally, we consider liquidity risk by taking the standard deviation of daily observations of the Amihud measure and Imputed Roundtrip Trades. These two measures do not separate total liquidity risk into a systematic and unsystematic component. Arguably, only the systematic component is important for pricing, but we find it difficult to measure this component on a frequent basis, so we calculate the total component and address the systematic component later in the paper.

Mahanti, Nashikkar, Subramanyam, Chacko, and Mallik (2008) infer a turnover measure for bonds from bond 
Table 1

Principal component loadings on the liquidity variables.

This table shows the principal component analysis loadings on each of the eight liquidity variables along with the cumulative explanatory power of the components. The liquidity variables are measured quarterly for each bond in the data sample. The data are U.S. corporate bond transactions data from TRACE and the sample period is from 2005:Q1 to 2009:Q2.

\begin{tabular}{|c|c|c|c|c|c|c|c|c|}
\hline \multicolumn{9}{|c|}{ Panel A: Principal component loadings, pre-subprime (2005:Q1-2007:Q1) } \\
\hline & $1 \mathrm{PC}$ & $2 \mathrm{PC}$ & 3PC & 4PC & $5 P C$ & $6 P C$ & 7PC & $8 \mathrm{PC}$ \\
\hline Amihud & 0.45 & 0.05 & -0.12 & -0.05 & 0.44 & 0.70 & -0.12 & 0.28 \\
\hline Roll & 0.26 & 0.33 & 0.08 & -0.86 & -0.27 & -0.06 & 0.06 & 0.02 \\
\hline Firm zero & -0.04 & 0.64 & -0.02 & 0.39 & -0.56 & 0.36 & 0.07 & 0.02 \\
\hline Bond zero & -0.00 & 0.67 & -0.10 & 0.10 & 0.56 & -0.45 & 0.05 & 0.11 \\
\hline Turnover & -0.02 & 0.07 & 0.98 & 0.07 & 0.15 & 0.08 & 0.01 & 0.03 \\
\hline IRC & 0.52 & 0.06 & 0.03 & 0.15 & 0.00 & -0.10 & -0.39 & -0.73 \\
\hline Amihud risk & 0.47 & -0.11 & 0.01 & 0.16 & -0.01 & -0.09 & 0.85 & -0.09 \\
\hline IRC risk & 0.49 & -0.12 & 0.06 & 0.21 & -0.29 & -0.40 & -0.31 & 0.60 \\
\hline Cum. \% explained & $39 \%$ & $59 \%$ & $72 \%$ & $81 \%$ & $89 \%$ & $94 \%$ & $99 \%$ & $100 \%$ \\
\hline \multicolumn{9}{|c|}{ Panel B: Principal component loadings, post-subprime (2007:Q2-2009:Q2) } \\
\hline & $1 \mathrm{PC}$ & $2 \mathrm{PC}$ & $3 P C$ & $4 P C$ & $5 P C$ & $6 P C$ & 7PC & $8 P C$ \\
\hline Amihud & 0.46 & 0.04 & -0.10 & -0.10 & -0.07 & 0.73 & 0.43 & 0.21 \\
\hline Roll & 0.06 & 0.47 & 0.35 & -0.78 & 0.10 & -0.02 & -0.17 & 0.02 \\
\hline Firm zero & -0.11 & 0.59 & -0.28 & 0.33 & 0.62 & 0.20 & -0.17 & 0.00 \\
\hline Bond zero & -0.12 & 0.64 & -0.07 & 0.21 & -0.67 & -0.16 & 0.21 & 0.12 \\
\hline Turnover & -0.14 & 0.05 & 0.88 & 0.39 & 0.08 & 0.20 & 0.12 & 0.01 \\
\hline IRC & 0.52 & 0.15 & 0.06 & 0.09 & 0.09 & -0.26 & 0.28 & -0.73 \\
\hline Amihud risk & 0.46 & 0.03 & 0.07 & 0.21 & -0.30 & 0.19 & -0.78 & -0.04 \\
\hline IRC risk & 0.51 & 0.02 & 0.09 & 0.13 & 0.23 & -0.51 & 0.10 & 0.63 \\
\hline Cum. \% explained & $39 \%$ & $58 \%$ & $71 \%$ & $81 \%$ & $88 \%$ & $94 \%$ & $99 \%$ & $100 \%$ \\
\hline
\end{tabular}

investors' portfolios, called latent liquidity. We are interested in yield spread effects of illiquidity, so we confine ourselves to the more liquid segment of the corporate bond market for which some prices are observed, and for this reason we do not use latent liquidity.

To see if most of the relevant information in the liquidity proxies can be captured by a few factors, we conduct a principal component (PC) analysis in Table 1 for the two periods 2005:Q1-2007:Q1 and 2007:Q2-2009:Q2. ${ }^{3}$ The explanatory power and the loadings of the first four PCs are stable in the two periods and we see that they have clear interpretations. The first component explains $40 \%$ of the variation in the liquidity variables and is close to an equally weighted linear combination of the Amihud and IRC measures and their associated liquidity risk measures. The second PC explains 20\% and is a zero-trading days measure, the third PC explains 13\% and is a turnover measure, and the fourth PC explains 9\% and is a Roll measure. The last four PCs explain less than $20 \%$ and do not have clear interpretations.

The principal component loadings on the first PC in Table 1 lead us to define a factor that loads evenly on Amihud, IRC, Amihud risk, and IRC risk, and does not load on the other liquidity measures. The factor is simpler to calculate than the first PC while retaining its properties. We add this factor to our liquidity proxies in our analysis and call it $\lambda$ (for details, see Appendix A).

\footnotetext{
${ }^{3}$ An extensive analysis of latent common factors in liquidity measures for equity markets can be found in Korajczyk and Sadka (2008).
}

\section{Liquidity premia}

\subsection{Summary statistics}

Table 2 shows summary statistics for the liquidity variables. We see that the median quarterly turnover is $4.5 \%$, meaning that for the average bond in the sample, it takes five to six years to turn over once. ${ }^{4}$ The median number of bond zero-trading days is $60.7 \%$, consistent with the notion that the corporate bond market is an illiquid market. We also see that the median number of firm zero-trading days is $0 \%$. This shows that although a given corporate bond might not trade very often, the issuing firm typically has some bond that is trading.

The median Amihud measure is 0.0044 implying that a trade of $\$ 300,000$ in an average bond moves price by roughly $0.13 \%$. Han and Zhou (2008) also calculate the Amihud measure for corporate bond data using TRACE data and find a much stronger price effect of a trade. For example, they find that a trade of $\$ 300,000$ in a bond, on average, moves the price by $10.2 \%$. This discrepancy is largely due to the exclusion of small trades in our sample and underscores the importance of filtering out retail trades when estimating transaction costs of institutional investors.

The median roundtrip cost in percentage of the price is $0.22 \%$ according to the IRC measure, while the roundtrip

\footnotetext{
4 The turnover is a lower bound on the actual turnover since trade sizes above $\$ 1 \mathrm{mil}$ ( $\$ 5 \mathrm{mil}$ ) for speculative (investment) grade bonds are registered as trades of size $\$ 1 \mathrm{mil}(\$ 5 \mathrm{mil})$.
} 
Table 2

Statistics for liquidity proxies.

This table shows statistics for corporate bond liquidity proxies. The proxies are calculated quarterly for each bond from 2005:Q1 to 2009:Q2. Panel A shows quantiles for the proxies. Panel B shows correlations among the proxies. The data are U.S. corporate bond transactions data from TRACE and the sample period is from 2005:Q1 to 2009:Q2. There is a total of 2,224 bond issues and 380 bond issuers in our sample.

\begin{tabular}{|c|c|c|c|c|c|c|c|c|c|}
\hline \multicolumn{10}{|c|}{ Panel A: Summary statistics for liquidity proxies } \\
\hline & $\lambda$ & Amihud & Roll & Firm zero & Bond zero & Turnover & IRC & Amihud risk & IRC risk \\
\hline 99th & 13.42 & 0.0813 & 8.39 & 92.1 & 96.8 & 0.247 & 0.0156 & 0.1592 & 0.01702 \\
\hline 95th & 7.44 & 0.0427 & 3.16 & 76.2 & 93.5 & 0.136 & 0.0096 & 0.0792 & 0.00997 \\
\hline 75th & 0.98 & 0.0120 & 1.05 & 12.5 & 79.7 & 0.070 & 0.0041 & 0.0298 & 0.00427 \\
\hline 50 th & -1.19 & 0.0044 & 0.53 & 0.0 & 60.7 & 0.045 & 0.0022 & 0.0147 & 0.00220 \\
\hline 25th & -2.85 & 0.0015 & 0.29 & 0.0 & 31.7 & 0.028 & 0.0012 & 0.0064 & 0.00102 \\
\hline 5 th & -3.08 & 0.0003 & 0.12 & 0.0 & 6.3 & 0.012 & 0.0005 & 0.0011 & 0.00024 \\
\hline $1 \mathrm{st}$ & -3.33 & 0.0000 & 0.06 & 0.0 & 0.0 & 0.005 & 0.0002 & 0.0002 & 0.00003 \\
\hline \multicolumn{10}{|c|}{ Panel B: Correlation matrix for liquidity proxies } \\
\hline & $\lambda$ & Amihud & Roll & Firm zero & Bond zero & Turnover & IRC & Amihud risk & IRC risk \\
\hline$\lambda$ & 1.00 & & & & & & & & \\
\hline Amihud & 0.83 & 1.00 & & & & & & & \\
\hline Roll & 0.17 & 0.16 & 1.00 & & & & & & \\
\hline Firm zero & -0.10 & -0.08 & 0.11 & 1.00 & & & & & \\
\hline Bond zero & -0.12 & -0.08 & 0.18 & 0.46 & 1.00 & & & & \\
\hline Turnover & -0.16 & -0.20 & 0.04 & 0.03 & 0.04 & 1.00 & & & \\
\hline IRC & 0.94 & 0.72 & 0.20 & -0.03 & -0.03 & -0.13 & 1.00 & & \\
\hline Amihud risk & 0.85 & 0.61 & 0.10 & -0.12 & -0.12 & -0.11 & 0.69 & 1.00 & \\
\hline IRC risk & 0.89 & 0.57 & 0.14 & -0.12 & -0.19 & -0.11 & 0.87 & 0.69 & 1.00 \\
\hline
\end{tabular}

cost is less than $0.05 \%$ for the $5 \%$ most liquid bonds. Thus, transaction costs are modest for a large part of the corporate bond market, consistent with findings in Edwards, Harris, and Piwowar (2007), Goldstein, Hotchkiss, and Sirri (2007), and Bessembinder, Maxwell, and Venkaraman (2006).

The correlations in Panel B of $87 \%$ between IRC and IRC risk and $61 \%$ between Amihud and Amihud risk show that liquidity and liquidity risk are highly correlated. This is consistent with results in Acharya and Pedersen (2005) who likewise find a high correlation between liquidity and liquidity risk. Interestingly, there is a high correlation of $72 \%$ between market depth (Amihud) and bid/ask spread (IRC). Panel B also shows that the Amihud measure is negatively correlated with firm zero, bond zero, and turnover, while the Roll measure has positive correlations with the three trading activity variables.

\subsection{Liquidity pricing}

To get a first-hand impression of the importance of liquidity, we regress in Table 3 corporate bond yield spreads on our liquidity variables one at a time while controlling for credit risk according to Eq. (1). ${ }^{5}$ We do this for five rating categories and before and after the onset of the subprime crisis. Running regressions for different rating categories shows how robust our conclusions are regarding the effect of liquidity. Furthermore, by splitting the sample into preand post-subprime, we see how liquidity is priced in two

\footnotetext{
${ }^{5}$ We only use observations for which an estimate for all measures exists. This ensures that the regression coefficients for all proxies are based on the same sample. We have also run the regressions where we allow an observation to enter a regression if the observation has an estimate for this liquidity proxy, although it might not have estimates of some of the other proxies. The results are very similar.
}

different regimes; the pre-subprime period was a period with plenty of liquidity while the market in the postsubprime period has suffered from a lack of liquidity.

Table 3 shows that transaction costs are priced, at least when we proxy bid-ask spreads with the IRC measure, consistent with the finding in Chen, Lesmond, and Wei (2007) that bid-ask spreads are priced. We also see that the Amihud measure has positive regression coefficients across all ratings and most of them are statistically significant. Furthermore, the regression coefficients for IRC risk and Amihud risk are positive and almost all significantly so.

The regression coefficients for turnover in the investment grade segment are negative in Table 3, while the reverse is the case for speculative grade bonds. This indicates that high turnover tends to reduce credit spreads for investment grade bonds but not for speculative grade bonds. The significance of the coefficients is modest though, so the evidence is not conclusive.

Turning to zero-trading days, Table 3 shows that there is no consistent relationship between the number of zerotrading days and spreads. If anything, the relationship tends to be negative since 14 out of 20 bond and firm zero regression coefficients are negative. This is surprising given that Chen, Lesmond, and Wei (2007) find that corporate bond spreads-when controlling for credit risk-depend positively on the number of zero-trading days. ${ }^{6}$

The weak link between zero-trading days and spreads is consistent with the theoretical results in Huberman and

\footnotetext{
${ }^{6}$ While we use actual transaction data, Chen, Lesmond, and Wei (2007) use data from Datastream and define a zero-trading day as a day where the price does not change. The working paper version of our paper has a graph (available on request) showing that there is very little relation between actual and Datastream zero-trading days. This might explain our different results.
} 
Table 3

Liquidity regressions.

For each rating class $R$ and each liquidity variable $L$ a pooled regression is run with credit risk controls

$$
\text { Spread }_{i t}^{R}=\alpha^{R}+\gamma^{R} L_{i t}+\text { Credit risk controls }{ }_{i t}+\epsilon_{i t},
$$

where $i$ is for bond in rating $R$ and $t$ is time measured in quarters. In total, 45 regressions are run (nine liquidity variables $\times$ five rating classes). This table shows for each regression the coefficient and $t$-statistics in parentheses for the liquidity variable. The proxies are described in detail in Section 3 and are calculated quarterly from 2005:Q1 to 2009:Q2. The data are U.S. corporate bond transactions from TRACE. Panel A shows the coefficients using data before the subprime crisis, while Panel B shows the coefficients using data after the onset of the subprime crisis. Standard errors are corrected for time series effects, firm fixed effects, and heteroskedasticity, and significance at $10 \%$ level is marked ${ }^{*}$, at $5 \%$ marked ${ }^{* *}$, and at $1 \%$ marked ${ }^{* * *}$.

\begin{tabular}{|c|c|c|c|c|c|}
\hline \multicolumn{6}{|c|}{ Panel A: Pre-subprime (2005:Q1-2007:Q1) } \\
\hline & AAA & AA & A & BBB & Spec \\
\hline$\lambda$ & $\begin{array}{c}0.0038^{* * * * *} \\
(2.97)\end{array}$ & $\underbrace{0.0056^{* * * * *}}_{(2.95)}$ & $\underset{(2.61)}{0.0131^{* * * *}}$ & $0_{(3.69)}^{0.0260^{* * * * *}}$ & $\begin{array}{c}0.1726^{* * * * *} \\
(5.34)\end{array}$ \\
\hline Amihud & $1.15^{* * * * *}$ & $\begin{array}{c}2.08^{* * * * * *} \\
(3.85)\end{array}$ & $\underset{(3.18)}{4.14 * * *}$ & $\begin{array}{l}3.68 \\
(1.52)\end{array}$ & $36.26^{* * 14)}$ \\
\hline Roll & $\frac{0.02^{\text {***** }}}{(3.18)}$ & $0.02^{* \text { ***** }}$ & $\begin{array}{l}0.01 \\
(1.48)\end{array}$ & $\begin{array}{l}0.02 \\
(0.53)\end{array}$ & $\underset{(-0.12)}{-0.01}$ \\
\hline Firm zero & 0.000 & -0.001 & 0.000 & $-\underset{(-1.66)}{0.001 *}$ & -0.010 \\
\hline Bond zero & -0.000 & $\begin{array}{l}-0.000 \\
(-0.86)\end{array}$ & ${ }_{(1.13)}^{0.000}$ & $-0.003^{* *}$ & $-0.024^{\text {***** }}$ \\
\hline Turnover & $-0.27^{* * * *}$ & -0.12 & -0.03 & $\begin{array}{l}-0.03 \\
(-0.18)\end{array}$ & $2_{(1.66)} .0{ }^{*}$ \\
\hline IRC & $\begin{array}{c}3.83^{* * *} \\
(2.03)\end{array}$ & $\begin{array}{l}7.11^{* * 6 * * *} \\
(2.66)\end{array}$ & $\underset{(2.61)}{18.91^{\text {****** }}}$ & $\underset{(3.76)}{47.47^{* * * * *}}$ & $\begin{array}{c}267.38^{* * * * *} \\
(4.82)\end{array}$ \\
\hline Amihud risk & $\begin{array}{l}0.39 * \\
(1.82)\end{array}$ & $\begin{array}{l}0.55^{*} \\
(1.87)\end{array}$ & $1.43^{* * *}$ & $\begin{array}{c}3.46^{* * * * *} \\
(3.46)\end{array}$ & $\underset{(5.03)}{22.92^{* * * *}}$ \\
\hline IRC risk & $\begin{array}{c}2.08^{* * *} \\
(2.30)\end{array}$ & $\begin{array}{l}3.98^{*} \\
(1.95)\end{array}$ & $\underset{(2.29)}{9.16^{* * *}}$ & $\underset{(3.18)}{25.99 * * *}$ & $\underset{(6.07)}{202.85^{* * * *}}$ \\
\hline \multicolumn{6}{|c|}{ Panel B: Post-subprime (2007:Q2-2009:Q2) } \\
\hline & AAA & AA & A & BBB & Spec \\
\hline$\lambda$ & $\underset{(2.12)}{0.0281^{* * *}}$ & $0.2495^{*}$ ***** & $0.2500^{* * * * *}$ & $0.3333^{* * * * *}$ & $\underset{(6.73)}{0.6746^{* * * * *}}$ \\
\hline Amihud & $\begin{array}{c}2.93^{* .98 * * *} \\
(2.98)\end{array}$ & $18.40_{(2.94)}^{* * * *}$ & $\begin{array}{l}6.80 \\
(0.82)\end{array}$ & $21.94^{* *}$ **. & $\begin{array}{c}84.58^{* * * * *} \\
(4.18)\end{array}$ \\
\hline Roll & $0.04^{* .58)}$ & -0.02 & $\begin{array}{l}0.04 \\
(0.87)\end{array}$ & $0.19^{*}$ & -0.58 \\
\hline Firm zero & -0.016 & $-\underset{(-0.03)}{-0.000}$ & $\underset{(-0.07)}{-0.000}$ & $-0.023^{* * 2.22)}$ & -0.022 \\
\hline Bond zero & $\frac{0.007^{\text {**a*k }}}{(7.26)}$ & $\begin{array}{l}0.002 \\
(0.73)\end{array}$ & ${ }_{(2.31)}^{0.013^{* *}}$ & -0.016 & 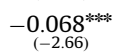 \\
\hline Turnover & $-\underset{(-11.87)}{-2.95 * * *}$ & -2.12 & $\begin{array}{l}-0.74 \\
(-0.31)\end{array}$ & $\underset{(-0.33)}{-2.97}$ & $\underset{(1.25)}{22.83}$ \\
\hline IRC & $\frac{20.50^{* * * * * *}}{(2.88)}$ & ${ }_{(3.08)}^{191.63^{* * * * * *}}$ & $\underset{(4.74)}{209.47^{* * * * *}}$ & $212.15^{*}$ *ak** & $\underset{(4.36)}{406.25^{* * * * *}}$ \\
\hline Amihud risk & $\begin{array}{l}1.99 \\
(1.25)\end{array}$ & $\underset{(4.74)}{18.87^{* * * * *}}$ & ${ }_{(3.26)}^{20.66^{* * * * *}}$ & $21.42^{* * * * *}$ & $\begin{array}{c}47.52 * * * * \\
(5.99)\end{array}$ \\
\hline IRC risk & ${ }_{(2.07)}^{17.40^{* *}}$ & $\underset{(3.71)}{167.60^{* * * * *}}$ & $190.46^{* * * * * *}$ & $270.28^{* * * * * *}$ & $\underset{(7.52)}{378.49^{* * * * * *}}$ \\
\hline
\end{tabular}

Stanzl (2005). They show that investors trade more often when price impact of trades is high, because they attempt to reduce the total price impact by submitting more but smaller orders. All else equal, more trades therefore occur in illiquid bonds since it is necessary to split a sell order in several trades, while it can be executed in a single trade in a liquid bond. ${ }^{7}$ If this explanation holds true, we should expect to see less zero-trading days in illiquid times

\footnotetext{
${ }^{7}$ Goldstein, Hotchkiss, and Sirri (2007) find that dealers behave differently when trading liquid and illiquid bonds. When trading liquid bonds they are more likely to buy the bond, have it as inventory, and sell it in smaller amounts. When trading illiquid bonds they quickly sell the entire position, so they perform more of a matching function in these bonds. This is consistent with our argument that illiquid bonds trade more often, which can be illustrated with the following example. In a liquid bond the investor sells $\$ 1,000,000$ to a dealer, who sells it to investors in two amounts of $\$ 500,000$. In an illiquid bond the investor sells $\$ 500,000$ to two different dealers, who each sell the $\$ 500,000$ to an investor. The total number of trades in the illiquid bond is four, while it is three in the liquid bond.
}

without an increase in the turnover. Fig. 1 shows that this is the case during the subprime crisis. The graph with the title 'Bond zero' shows that the average percentage zerotrading days decreases during the subprime crisis while the graph with the title 'Turnover' shows that turnover decreases slightly. Drawing conclusions from Fig. 1 might be misleading since a bond in a given quarter is only included in the sample if it has a full set of accounting variables and trades at least four times that quarter. To address the concern that this may bias zero-trading days over time, Fig. 2 shows the time series of quarterly average number of trades and average trade size for all straight coupon bullet bonds in our sample period. The graph shows that there was an increase in the average number of trades and a decrease in the average trade size during the subprime crisis.

Table 3 also shows that $\lambda$ is significant for all rating categories pre- and post-subprime. For nine out of ten regression coefficients, the significance is at a $1 \%$ level. Compared to previously proposed liquidity proxies, zerotrading days (Chen, Lesmond, and Wei, 2007), and the Roll 

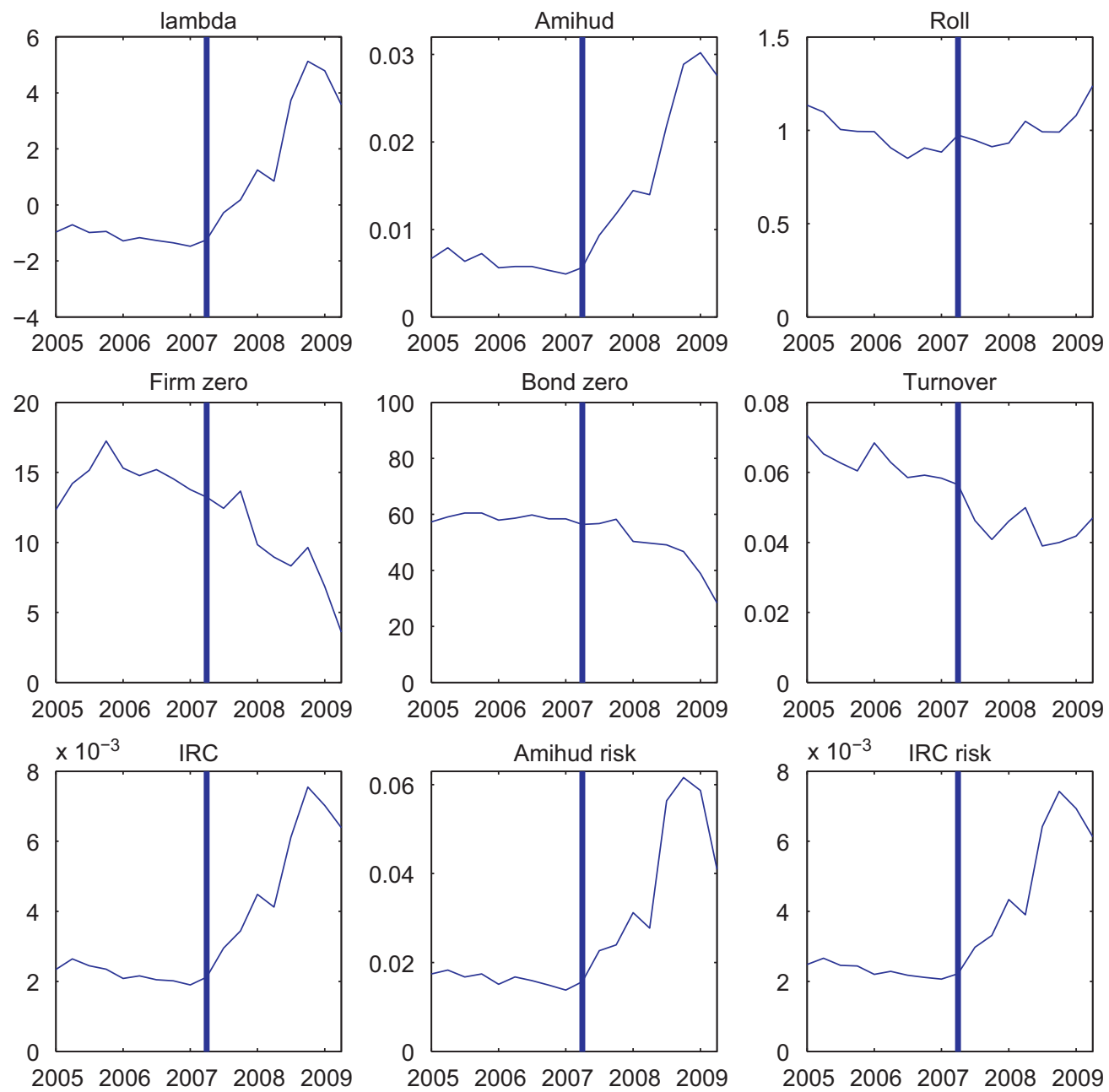

Fig. 1. Time series of liquidity variables. This graph plots the time series of liquidity variables along with a line marking the start of the subprime crisis (beginning in 2007:Q2). The data are U.S. corporate bond transactions from TRACE and the sample period is from 2005:Q1 to 2009:Q2. Liquidity variables are measured quarterly for each bond, and for every liquidity variable the mean value of the variable across all bonds each quarter is graphed.

measure (Bao, Pan, and Wang, 2011), $\lambda$ is a more consistent proxy for liquidity. Therefore, we use $\lambda$ as our liquidity measure in the rest of the paper.

The liquidity measure $\lambda$ and its four individual components all provide the same evidence regarding the compensation for holding illiquid bonds: since the regression coefficients in Table 3 increase post-subprime, investors require a larger compensation for investing in illiquid bonds. Furthermore, illiquidity has increased as Fig. 1 shows, so the impact of illiquidity on yield spreads is twofold: through an increase in illiquidity and through a higher risk premium on illiquidity.

\subsection{Size of liquidity component}

To calculate the impact of corporate bond illiquidity on yield spreads, we do the following. For each rating $R$ and in both regimes, we run the pooled regression

Spread $_{i t}^{R}=\alpha^{R}+\beta^{R} \lambda_{i t}+$ Credit risk controls $s_{i t}+\epsilon_{i t}$, where $i$ refers to bond, $t$ to time (measured in quarters of year), and $\lambda_{i t}$ is our liquidity measure. We define the liquidity score for a bond in a given quarter as $\beta^{R} \lambda_{i t}$. Within each rating (AAA, AA, A, BBB, Spec), period (pre- or post-subprime), and maturity (0-2y, 2-5y, 5-30y) we sort all observations according to their liquidity score. The liquidity component of an average bond is defined as the $50 \%$ quantile minus the $5 \%$ quantile of the liquidity score distribution. Thus, the liquidity component measures the difference in bond yields between a bond with average liquidity and a very liquid bond. This approach allows us to look directly at the importance of liquidity by estimating how much $\lambda$ contributes to corporate bond spreads, instead of defining liquidity as a residual after controlling for credit risk. In particular, the difference between corporate bond spreads and CDS premia is often used as a proxy for liquidity. For example, Longstaff, Mithal, and Neis (2005) subtract CDS premia from corporate bond spreads to arrive at a liquidity component of credit spreads. However, the CDS spread is often larger than the comparable bond spread 

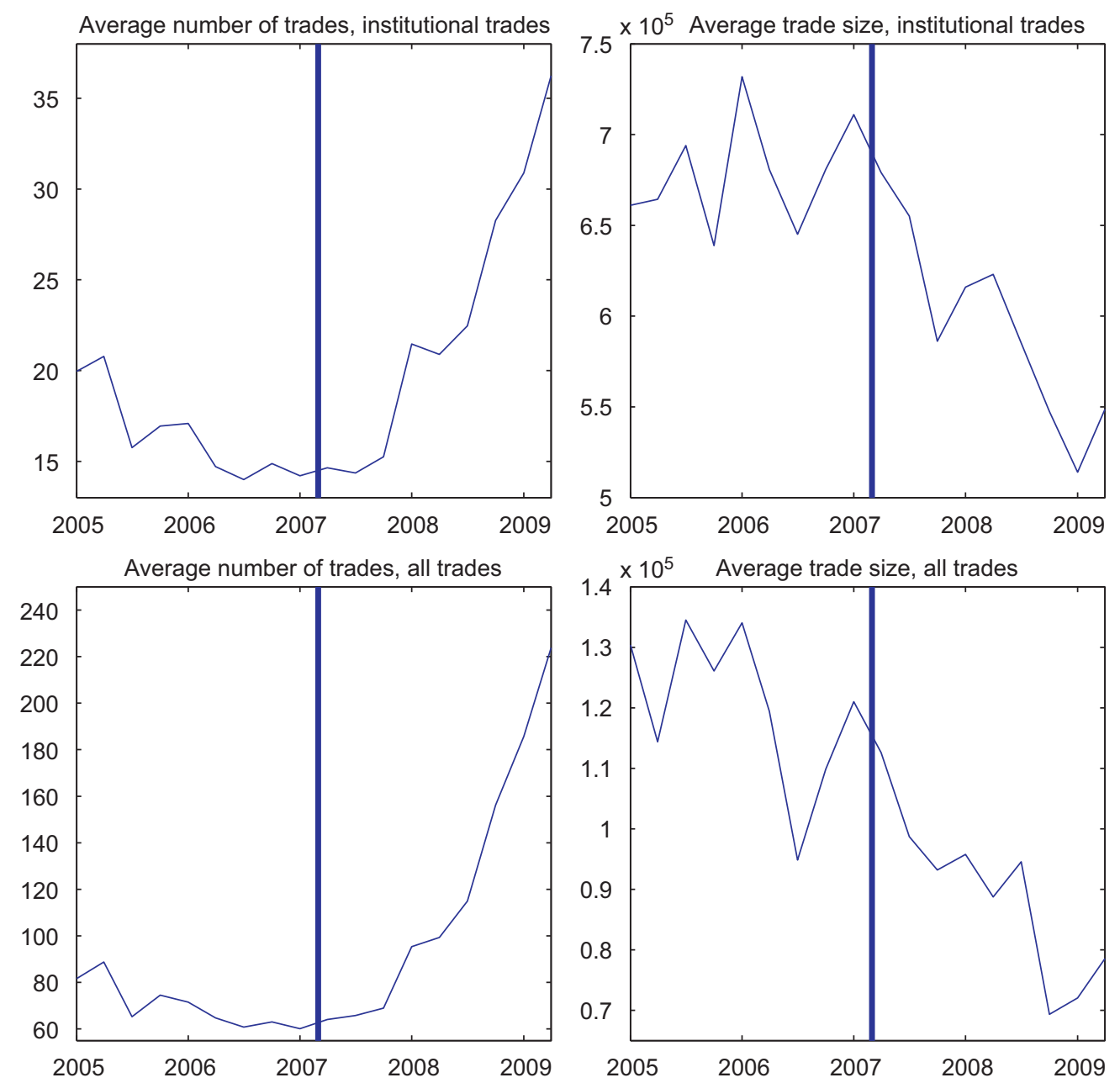

Fig. 2. Time series of average number of trades and average trade size in the full sample. This graph plots the time series of average number of trades and average trade size in a quarter for a corporate bond along with a line marking the start of the subprime crisis (beginning in 2007:Q2). The data are U.S. corporate bond transactions from TRACE and the sample period is from 2005:Q1 to 2009:Q2. A bond is included in every quarter if it traded at least one time during the sample period 2005:Q1-2009:Q2. The top graphs are based on institutional trades, i.e., trades of size \$100,000 or more, while the bottom graphs are based on all trades.

leading to a negative liquidity component. In fact, Han and Zhou (2008) find the average implied liquidity component for speculative grade bonds to be negative. Furthermore, Bongaerts, Driessen, de Jong (2011) find that there are also liquidity components in CDS spreads.

Table 4 shows the size of the liquidity component. Following Cameron, Gelbach, and Miller (2008), we calculate confidence bands by performing a wild cluster bootstrap of the regression residuals. We see that the liquidity component becomes larger as the rating quality of the bond decreases. For investment grade ratings, the component is small with an average pre-subprime across maturity of $0.8 \mathrm{bp}$ for AAA, $1.0 \mathrm{bp}$ for AA, $2.4 \mathrm{bp}$ for A, and $3.9 \mathrm{bp}$ for $\mathrm{BBB}$. For speculative grade, the liquidity component is larger and estimated to be $57.6 \mathrm{bp}$.

There is a strong increase in the liquidity component in the post-subprime period as Panel B in Table 4 shows. The component increases by a factor of 10 or more in investment grade bonds of rating $\mathrm{AA}, \mathrm{A}$, and $\mathrm{BBB}$ while it increases by a factor of 3-4 in speculative grade bonds. This shows that liquidity has dried out under the subprime crisis and part of the spread-widening for bonds is due to a higher liquidity premium.

While liquidity components in all ratings increase, we see that the increase in AAA bonds is modest. Even after the onset of the subprime crisis the component is $8 \mathrm{bp}$ or less, which is small compared to the component of other bonds. We see in Table 3 that the regression coefficient for AAA on $\lambda$ is small post-subprime compared to those of other rating classes, so the sensitivity of AAA-rated bonds to liquidity is small. This suggests that a flight-to-quality leads investors into buying AAA-rated bonds regardless of their liquidity.

The average liquidity premium in speculative grade bonds is 57.6bp pre-subprime, so even in this liquidity-rich period speculative grade bonds commanded a sizeable liquidity premium. Post-subprime, the liquidity premium increased to $196.8 \mathrm{bp}$. An A-rated bond has an average 
Table 4

Liquidity component in basis points.

For each rating $R$, we run the pooled regression

$$
\text { Spread }_{i t}^{R}=\alpha^{R}+\beta^{R} \lambda_{i t}+\text { Credit risk controls }{ }_{i t}+\epsilon_{i t},
$$

where $i$ refers to bond, $t$ to time, and $\lambda_{i t}$ is our liquidity measure. The bond spread is measured with respect to the swap rate. Within each rating and maturity bucket $\left(0-2 y, 2-5 y\right.$, and $5-30 y$ ), we sort increasingly all values of $\lambda_{i t}$ and find the median value $\lambda_{50}$ and the $5 \%$ value $\lambda_{5}$. The liquidity component in the bucket is defined as $\beta\left(\lambda_{50}-\lambda_{5}\right)$. This table shows for all buckets the liquidity component with standard errors in parentheses. Confidence bands are found by a wild cluster bootstrap. The data are U.S. corporate bond transactions from TRACE and the sample period is from 2005:Q1 to 2009:Q2.

Panel A: Liquidity component in basis points, pre-subprime (2005Q1-2007:Q1)

\begin{tabular}{|c|c|c|c|c|c|c|c|}
\hline & \multirow[t]{2}{*}{ Average } & \multicolumn{3}{|c|}{ Liquidity component, basis points } & \multicolumn{3}{|c|}{ Number of observations } \\
\hline & & $0-2 y$ & $2-5 y$ & $5-30 y$ & $0-2 y$ & $2-5 y$ & $5-30 y$ \\
\hline AAA & 0.8 & $\begin{array}{c}0.6 \\
(0.3 ; 0.8)\end{array}$ & $\begin{array}{c}0.9 \\
(0.5 ; 1.3)\end{array}$ & $\begin{array}{l}1.1 \\
(0.6 ; 1.5)\end{array}$ & 162 & 178 & 193 \\
\hline AA & 1.0 & $\begin{array}{c}0.7 \\
(0.3 ; 1.1)\end{array}$ & $\begin{array}{c}1.0 \\
(0.4 ; 1.7)\end{array}$ & $\begin{array}{c}1.3 \\
(0.5 ; 2.2)\end{array}$ & 704 & 667 & 498 \\
\hline A & 2.4 & $\begin{array}{c}1.5 \\
(0.6 ; 2.3)\end{array}$ & 2.5 & $\begin{array}{c}3.2 \\
(1.4 ; 4.9)\end{array}$ & 1540 & 1346 & 1260 \\
\hline BBB & 3.9 & $\begin{array}{c}2.8 \\
(1.4 ; 4.4)\end{array}$ & $\begin{array}{c}4.0 \\
(1.9 ; 6.2)\end{array}$ & $\begin{array}{c}4.7 \\
(2.3 ; 7.3)\end{array}$ & 517 & 270 & 553 \\
\hline Spec & 57.6 & $\begin{array}{c}45.0 \\
(32.3 ; 57.4)\end{array}$ & $\begin{array}{c}44.0 \\
(31.5 ; 56.0)\end{array}$ & $\begin{array}{c}83.9 \\
(60.2 ; 106.8)\end{array}$ & 270 & 324 & 480 \\
\hline
\end{tabular}

Panel B: Liquidity component in basis points, post-subprime (2007:Q2-2009:Q2)

\begin{tabular}{|c|c|c|c|c|c|c|c|}
\hline & \multirow[t]{2}{*}{ Average } & \multicolumn{3}{|c|}{ Liquidity component, basis points } & \multicolumn{3}{|c|}{ Number of observations } \\
\hline & & $0-2 y$ & $2-5 y$ & $5-30 y$ & $0-2 \mathrm{y}$ & $2-5 y$ & $5-30 y$ \\
\hline AAA & 4.9 & $\begin{array}{c}2.5 \\
(0.5 ; 4.4)\end{array}$ & $\begin{array}{c}4.5 \\
(0.9 ; 8.0)\end{array}$ & $\begin{array}{c}779 \\
(1.7 ; 14.1)\end{array}$ & 110 & 149 & 155 \\
\hline AA & 41.8 & $\begin{array}{c}23.5 \\
(12.9 ; 33.2)\end{array}$ & $\begin{array}{c}37.1 \\
(20.3 ; 52.4)\end{array}$ & $\begin{array}{c}64.7 \\
(35.5 ; 91.4)\end{array}$ & 493 & 572 & 483 \\
\hline A & 50.7 & $\begin{array}{c}26.6 \\
(15.3 ; 39.2)\end{array}$ & $\begin{array}{c}51.0 \\
(29.3 ; 75.1)\end{array}$ & $\begin{array}{c}74.5 \\
(42.9 ; 109.7)\end{array}$ & 762 & 878 & 890 \\
\hline BBB & 92.7 & $\begin{array}{c}64.3 \\
(36.5 ; 92.7)\end{array}$ & $\begin{array}{c}115.6 \\
(65.6 ; 166.6)\end{array}$ & $\begin{array}{c}98.1 \\
(55.7 ; 141.4)\end{array}$ & 123 & 159 & 256 \\
\hline Spec & 196.8 & $\begin{array}{c}123.6 \\
(80.2 ; 157.3)\end{array}$ & $\begin{array}{c}224.0 \\
(145.3 ; 285.1)\end{array}$ & $\begin{array}{c}242.7 \\
(157.4 ; 308.8)\end{array}$ & 133 & 129 & 201 \\
\hline
\end{tabular}

liquidity premium of 50.7bp post-subprime, so the illiquidity of such a bond post-subprime is similar to that of a speculative grade bond pre-subprime.

The size of the liquidity component in investment grade spreads pre-subprime is comparable in magnitude to the nondefault component found by subtracting the CDS premium from the corporate-swap spread (swap basis); see Longstaff, Mithal, and Neis (2005), Blanco, Brennan, and Marsh (2005), and Han and Zhou (2008). ${ }^{8}$ These papers look at recent periods before the subprime crisis and our presubprime results agree with their results in that there is a modest liquidity premium in investment grade corporate bond yields. The nondefault component for speculative bonds extracted from the swap basis is smaller and often negative, and the evidence presented here suggests that other factors than corporate bond liquidity are important for explaining the basis for speculative grade bonds. ${ }^{9}$

\footnotetext{
${ }^{8}$ Longstaff, Mithal, and Neis (2005) find an average nondefault component of $-7.2 \mathrm{bp}$ for AAA/AA, 10.5bp for A, and 9.7bp for BBB, Han and Zhou (2008) find the nondefault component to be 0.3bp for AAA, 3.3bp for AA, 6.7bp for A, and 23.5bp for BBB, while Blanco, Brennan, and Marsh (2005) find it to be $6.9 \mathrm{bp}$ for AAA/AA, $0.5 \mathrm{bp}$ for A, and $14.9 \mathrm{bp}$ for BBB.

${ }^{9}$ Longstaff, Mithal, and Neis (2005) report an average of $17.6 \mathrm{bp}$ for $\mathrm{BB}$, while Han and Zhou (2008) estimate it to be $2.8 \mathrm{bp}$ for BB, $-53.5 \mathrm{bp}$ for $\mathrm{B}$, and $-75.4 \mathrm{bp}$ for $\mathrm{CCC}$.
}

Turning to the term structure of liquidity, the general pattern across ratings and regime is that the liquidity component increases as maturity increases. Overall, the premium in basis points is around twice as high for long maturity bonds compared to short maturity bonds. Ericsson and Renault (2006) and Feldhütter (in press) find that the liquidity premium due to selling pressure-sales at discounted prices by liquidity-shocked investors-is downward sloping. Furthermore, Feldhütter (in press) finds that the liquidity premium due to search costs, the cost incurred because it takes time to find a counterparty, also is downward sloping. Our contrasting results might be because $\lambda$ is a combination of liquidity measures, and in addition to selling pressure and search costs, measures additional aspects of illiquidity such as liquidity risk. To decompose liquidity premia into individual components and across maturity is interesting but outside the scope of this paper.

We also compute the fraction of the liquidity component to the total spread. For each bond we proceed as follows. We define the bond's liquidity component as $\beta^{R}\left(\lambda_{i t}-\lambda_{5 t}\right)$, where $\lambda_{5 t}$ is the $5 \%$ quantile of the liquidity measure. The liquidity component is then divided by the bond's yield spread and within each group we find the median liquidity fraction. We show in Appendix B that the size of the liquidity component is robust to the choice of benchmark riskfree rate, but the liquidity fraction of the total spread is sensitive to the benchmark. The swap 
Table 5

Liquidity component in fraction of spread.

For each rating $R$, we run the pooled regression

$$
\text { Spread }_{i t}^{R}=\alpha^{R}+\beta^{R} \lambda_{i t}+\text { Credit risk controls }{ }_{i t}+\epsilon_{i t},
$$

where $i$ refers to bond, $t$ to time, and $\lambda_{i t}$ is our liquidity measure. Within each rating we sort increasingly all values of $\lambda_{i t}$ and find the $5 \%$ value $\lambda_{5}$. For each bond we define the liquidity fraction of the total spread as $\beta^{R}\left(\lambda_{i t}-\lambda_{5}\right) / \operatorname{Spread}_{i t}^{R}$. The estimated fractions in the table are for each entry the median fraction. Confidence bands are found by a wild cluster bootstrap. The data are U.S. corporate bond transactions from TRACE and the sample period is from 2005:Q1 to 2009:Q2.

\begin{tabular}{|c|c|c|c|c|c|c|c|c|}
\hline Maturity & $0-1 y$ & $1-2 y$ & $2-3 y$ & $3-4 y$ & $4-5 y$ & $5-8 y$ & $8-10 y$ & $10-30 y$ \\
\hline Fraction in pct & $\begin{array}{c}3 \\
(2 ; 4)\end{array}$ & $\begin{array}{c}7 \\
(4 ; 9)\end{array}$ & $\begin{array}{c}13 \\
(8 ; 17)\end{array}$ & $\begin{array}{c}13 \\
(8 ; 18)\end{array}$ & $\begin{array}{c}13 \\
(8 ; 17)\end{array}$ & $\begin{array}{c}11 \\
(7 ; 15)\end{array}$ & $\begin{array}{c}8 \\
(5 ; 11)\end{array}$ & $\begin{array}{c}10 \\
(7 ; 14)\end{array}$ \\
\hline Number of observations & 1596 & 1613 & 1241 & 891 & 641 & 1187 & 578 & 1218 \\
\hline Rating & AAA & $\mathrm{AA}$ & A & BBB & Spec & & & \\
\hline Fraction in pct & $\begin{array}{c}3 \\
(2 ; 5)\end{array}$ & $\begin{array}{c}4 \\
(2 ; 7)\end{array}$ & $\begin{array}{c}11 \\
(5 ; 18)\end{array}$ & $\underset{(3 ; 12)}{8}$ & $\underset{(18 ; 30)}{24}$ & & & \\
\hline Number of observations & 533 & 1869 & 4148 & 1340 & 1075 & & & \\
\hline \multicolumn{9}{|c|}{ Panel B: Liquidity component in fraction of spread, post-subprime (2007:Q2-2009:Q2) } \\
\hline Maturity & $0-1 \mathrm{y}$ & $1-2 y$ & $2-3 y$ & $3-4 y$ & $4-5 y$ & $5-8 y$ & $8-10 y$ & $10-30 y$ \\
\hline Fraction in pct & $\underset{(7 ; 14)}{11}$ & $\underset{(13 ; 27)}{20}$ & $\begin{array}{c}23 \\
(15 ; 31)\end{array}$ & $\underset{(18 ; 38)}{27}$ & $\begin{array}{c}31 \\
(20 ; 42)\end{array}$ & $\begin{array}{c}44 \\
(28 ; 60)\end{array}$ & $\begin{array}{c}33 \\
(21 ; 44)\end{array}$ & $\begin{array}{c}43 \\
(28 ; 53)\end{array}$ \\
\hline Number of observations & 809 & 819 & 675 & 657 & 556 & 817 & 568 & 598 \\
\hline Rating & AAA & $\mathrm{AA}$ & A & BBB & Spec & & & \\
\hline Fraction in pct & $\underset{(1 ; 12)}{7}$ & $\underset{(23 ; 60)}{42}$ & $\underset{(14 ; 39)}{26}$ & $\underset{(16 ; 41)}{29}$ & $\underset{(16 ; 30)}{23}$ & & & \\
\hline Number of observations & 414 & 1549 & 2533 & 539 & 464 & & & \\
\hline
\end{tabular}

rate is chosen because there is mounting evidence that swap rates are better proxies for riskfree rates than Treasury yields (see, for example, Hull, Predescu, and White, 2004; Feldhütter and Lando, 2008).

Table 5 shows the fraction of the liquidity component to the total corporate-swap spread. The first parts of Panels A and $\mathrm{B}$ sort according to rating. We see that the fraction of spreads due to illiquidity is small for investment grade bonds, $11 \%$ or less. Using the ratio of the swap basis relative to the total spread, Longstaff, Mithal, and Neis (2005) find the fraction of spread due to liquidity at the 5-year maturity to be $2 \%$, while Han and Zhou (2008) find it to be $19 \%$ consistent with our finding that it is relatively small. In speculative grade bonds the fraction due to liquidity is $24 \%$. Postsubprime, the fractions increase and range from $23 \%$ to $42 \%$ in all ratings but AAA where it is only $7 \%$. That the liquidity fractions of spreads in AAA are small in percent relative to other bonds underscores that there is a flight-to-quality effect in AAA bonds. A consistent finding from Tables 4 and 5 is that for investment grade bonds the importance of liquidity has increased after the onset of the subprime crisis both in absolute size (basis points) and relative to credit risk (fraction of spread). For speculative grade bonds the liquidity component in basis points has increased but it is stable measured as the fraction of total yield spread.

The last parts of Panels A and B in Table 5 show the liquidity fraction of total spread as a function of maturity. We introduce a fine maturity grid but do not sort according to rating to have a reasonable sample size in each bucket. We see that the fraction of the spread due to liquidity is small at short maturities and becomes larger as maturity increases. This is the case both pre- and postsubprime, although the fraction is higher post-subprime for all maturities. For example, post-subprime, the fraction of spread due to liquidity is $43 \%$ for bonds with a maturity more than ten years while it is $11 \%$ for maturities less than one year. The fraction increases at maturities shorter than five years and thereafter flattens. The slight dip at the $8-10 \mathrm{y}$ maturity both pre- and postsubprime is due to an on-the-run effect; many bonds are issued with a maturity of ten years and are more liquid right after issuance. ${ }^{10}$

We find strong differences in the pre- and post-subprime periods, and to examine the variation within the two periods more closely, we estimate monthly variations in liquidity and spreads as follows. Each month we (a) find a regression coefficient $\beta_{t}$ by regressing spreads on $\lambda$ while controlling for credit risk, (b) calculate for each bond the fraction due to illiquidity, $\beta_{t}\left(\lambda_{i t}-\lambda_{5 t}\right) /$ spread $_{i t}$, (c) find the median fraction, and (d) multiply this fraction by the median spread. This gives us the total liquidity premium in basis points on a monthly basis. We do this for investment grade and speculative grade bonds separately. ${ }^{11}$ This measures the amount of the total spread that is due to illiquidity. Fig. 3 shows the time-series variation in the median spread and the amount of the spread due to illiquidity.

The liquidity premium in investment grade bonds is persistent and steadily increasing during the subprime crisis and peaks in the first quarter of 2009 when stock prices decreased strongly. We see that the co-movement between the liquidity premium and credit spread is quite high. For

\footnotetext{
${ }^{10}$ To support this claim, we additionally sorted according to bond age (older and younger than two years). After this sort, the dip at the $8-10 y$ maturity was not present. Results are available on request.

11 The results become unstable if we split into finer rating categories. While the quantiles of $\lambda$ can be determined reasonably well, the regression coefficient $\beta_{t}^{R}$ becomes noisy.
} 

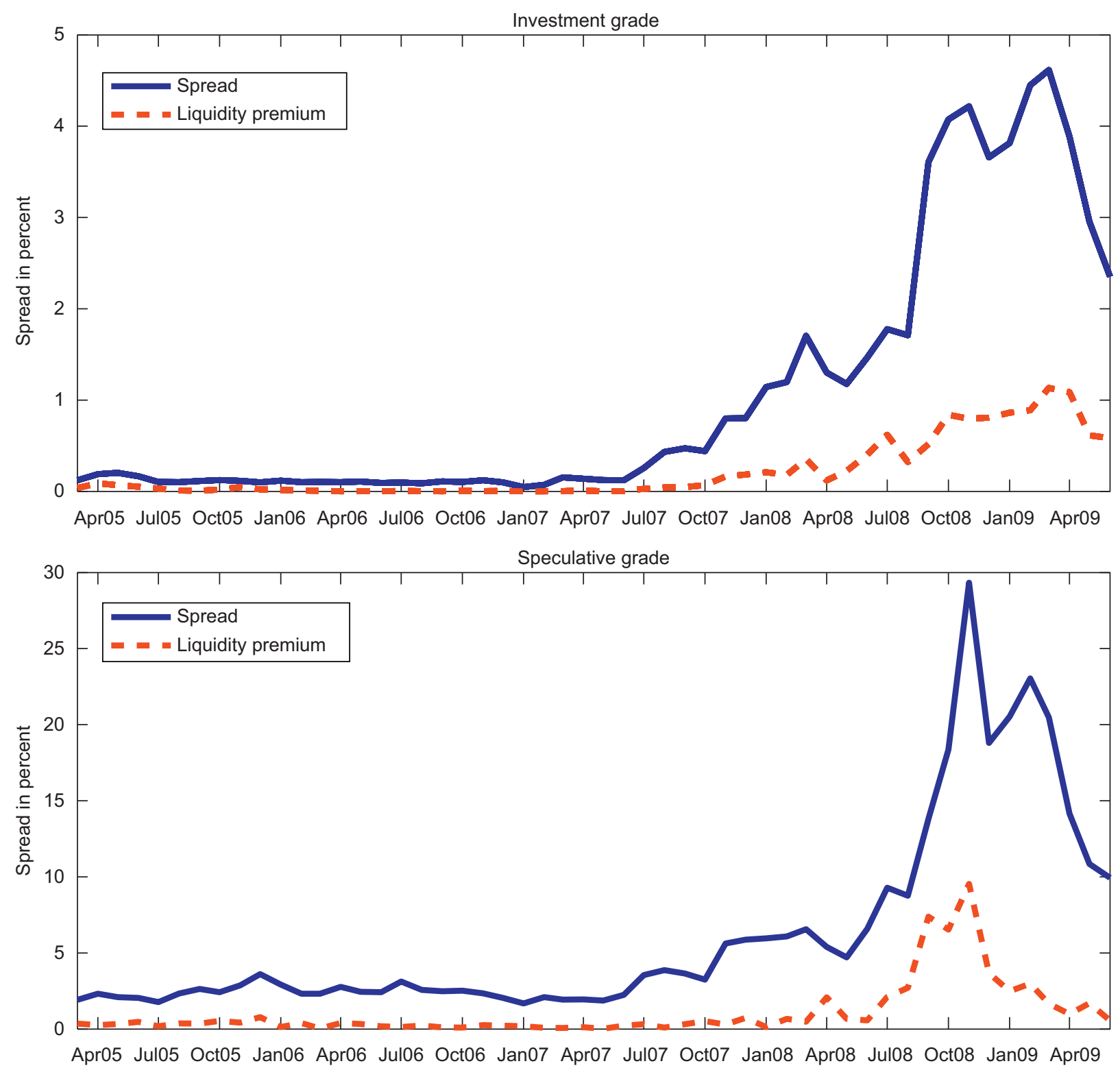

Fig. 3. Liquidity premium and total spread for investment grade and speculative grade bonds. This graph shows for investment grade and speculative grade yield spreads the variation over time in the amount of the spread that is due to illiquidity and the total yield spread. On a monthly basis, the fraction of the yield spread that is due to illiquidity is calculated as explained in Section 4.3. This fraction multiplied by the median yield spread is the amount of the spread due to illiquidity and plotted along with the median yield spread. The data are U.S. corporate bond transactions from TRACE and the sample period is from 2005:Q1 to 2009:Q2.

speculative grade bonds, the liquidity premium peaks around the bankruptcy of Lehman and shows less persistence. Furthermore, the co-movement between the liquidity premium and the spread is less pronounced than for investment grade bonds, and the premium at the end of the sample period is almost down to pre-crisis levels even though the spread is still higher than before the crisis.

\section{Determinants of bond illiquidity}

In this section, we use our measure of liquidity to document some key mechanisms by which corporate bond illiquidity is affected. Specifically, we focus on the liquidity of bonds with a lead underwriter in financial distress, the liquidity of bonds issued by financial firms relative to bonds issued by industrial firms, and liquidity betas.

\subsection{Lead underwriter}

Brunnermeier and Pedersen (2009) provide a model that links an asset's market liquidity and traders' funding liquidity, and find that when funding liquidity is tight, traders become reluctant to take on positions, especially 'capital intensive' positions in high-margin securities. This lowers 
market liquidity. Empirical support for this prediction is found in Comerton-Forde, Hendershott, Jones, Moulton, and Seasholes (2010) who find for equities traded on NYSE that balance sheet and income statement variables for market makers explain time variation in liquidity.

Since the TRACE data do not reveal the identity of the traders, we cannot perform direct tests of the Brunnermeier and Pedersen (2009)-model for the U.S. corporate bond market. However, if we assume that the original underwriter is more likely to make a market as is the case in equity markets, see Ellis, Michaely, and O'Hara (2000), we can provide indirect evidence by observing bond liquidity of bonds underwritten by Bear Stearns and Lehman Brothers, two financial institutions in distress during the subprime crisis. We therefore calculate for all bonds with Lehman Brothers as lead underwriter their average $\lambda$-weighted by amount outstanding — on a monthly basis. Likewise, we do this for bonds with Bear Stearns as lead underwriter and for all other bonds that are not included in the Bear Stearns and Lehman samples. We obtain underwriter information from the Fixed Income Securities Database (FISD). The results are plotted in Fig. 4.

The liquidity of bonds with Bear Stearns as lead underwriter was roughly the same as an average bond entering in the summer of 2007. During the week of July 16, 2007, Bear Stearns disclosed that two of their hedge funds had lost nearly all of the value, and the graph shows that the 'illiquidity gap' between Bear Stearns underwritten bonds and average bonds increased that month. On August 6, Bear Stearns said that it was weathering the worst storm in financial markets in more than 20 years, in November 2007 Bear Stearns wrote down $\$ 1.62$ billion and booked a fourth quarter loss, and in December 2007 there was a further write-down of $\$ 1.90$ billion. During these months, the 'illiquidity gap' steadily increased. Bear Stearns was in severe liquidity problems in the beginning of March, and they were taken over by JP Morgan on March 16. In this month the 'illiquidity gap' peaked but returned to zero in June 2008 after Bear Stearns shareholders approved JP Morgan's buyout of the investment bank on May 29.

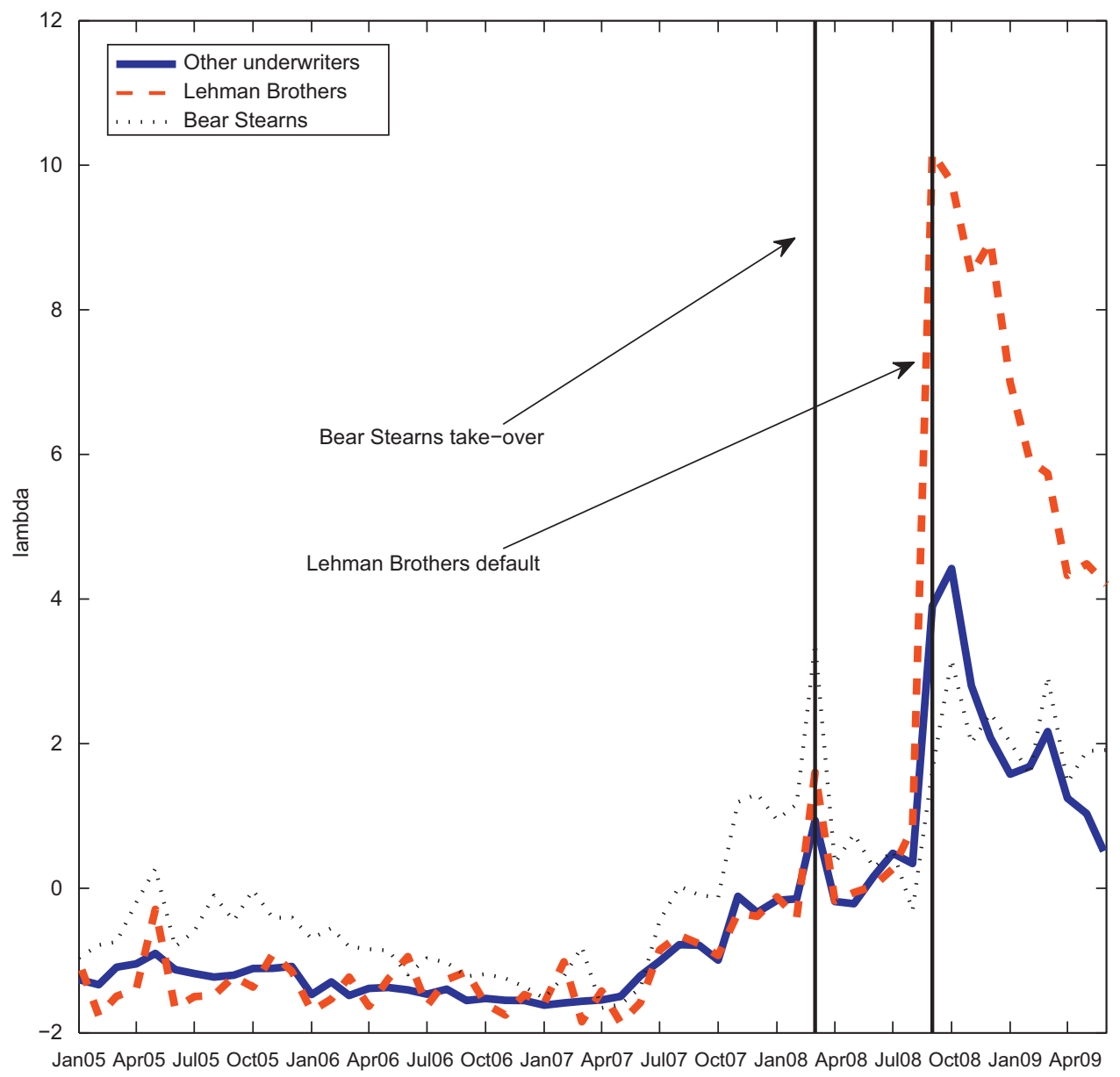

Fig. 4. Illiquidity of bonds underwritten by Lehman Brothers and Bear Stearns. This graph shows the time-series variation in illiquidity of bonds with Lehman Brothers as lead underwriter, bonds with Bear Stearns as lead underwriter, and the rest of the sample. The data are U.S. corporate bond transactions from TRACE and the sample period is from 2005:Q1 to 2009:Q2. For every bond underwritten by Lehman Brothers, their (il)liquidity measure $\lambda$ is calculated each month and a monthly weighted average is calculated using amount outstanding for each bond as weight. The graph shows the time series of monthly averages. Likewise, a time series of monthly averages is calculated for bonds with Bear Stearns as a lead underwriter and for all bonds that are not included in the Lehman and Bear Stearns samples. Higher values on the $y$-axis imply more illiquid bonds. 
In particular, this buyout meant that JP Morgan assumed Bear Stearns' trading business, and the 'illiquidity gap' returning to zero is consistent with the market's perception of JP Morgan as being well-capitalized.

The liquidity of bonds underwritten by Lehman was close to the liquidity of an average bond in the market up until August 2008, but this changed when the 'illiquidity gap' between Lehman underwritten bonds and average market bonds increased strongly in response to Lehman filing for bankruptcy on September 15. On September 17, Barclays announced that it acquired Lehman's North American trading unit. The gap stayed at high levels during the rest of the sample period showing that after the Lehman default, bonds they had underwritten became permanently more illiquid. This suggests that a bankruptcy (Lehman) has a permanent effect on the illiquidity of underwritten bonds while a takeover (Bear Stearns) has a temporary effect. The permanent effect caused by bankruptcy might be because the default left Barclays with more pressing issues after the acquisition than resuming market-making activities linked to underwritten bonds. Another contributing factor could be that a counterparty with which Lehman had a relationship as broker was more likely to hold bonds underwritten by Lehman. These bonds might be held by Lehman as collateral if Lehman financed the counterparty. After the default the collateral could not easily be returned, as explained in Aragon and Strahan (in press), and therefore could not be traded by the counterparty leading to a loss in market liquidity in that bond. Aragon and Strahan (in press) study hedge funds with a broker relationship with Lehman. Consistent with our findings, they find (a) a permanent loss in liquidity of assets traded by these hedge funds after the Lehman default, and (b) no permanent effect during the Bear Stearns takeover in the case of Bear Stearns being the broker. ${ }^{12}$

\subsection{Industry}

The yield spreads on bonds issued by financial firms peaked around key events of the subprime crisis. Concerns about the credit quality of financial firms were of course a main driver behind these spread widenings, but it is conceivable that deteriorating liquidity of their bond issues was also a factor. We address this issue by calculating an average (weighted by amount outstanding) monthly $\lambda$ of financial and industrial firms, respectively, and plotting the timeseries behavior in Fig. 5. We obtain bond issuer characteristics from FISD.

In general, there is little systematic difference. For both financial and industrial bonds, illiquidity goes up at the onset of the crisis. There are, however, additional spikes in illiquidity for financial firms around the takeover of Bear Stearns in March 2008, around the Lehman bankruptcy in September 2008, and around the stock market decline in the first

\footnotetext{
12 In results not reported we have also looked at bonds underwritten by Merrill Lynch. In these bonds there is an increase in illiquidity relative to other bonds in the months leading up to September 2008 when Merrill Lynch was taken over by Bank of America. After the takeover, this 'run-up' disappears so the effect is temporary as in the Bear Stearns case. A graph is available on request.
}

quarter of 2009. That is, in times of severe financial distress, illiquidity of financial bonds increases relative to that of industrial bonds, while in other times liquidity is similar. This pattern might be due to the heightened information asymmetry regarding the state of the financial firms-including their financial linkages - around the dramatic events.

By calculating monthly averages, we are able to draw more high-frequency inferences compared to Longstaff, Mithal, and Neis (2005) and Friewald, Jankowitsch, and Subrahmanyam (forthcoming). If we average $\lambda$ over longer periods of time, as in the approach taken in those two papers, the effects we find would be washed out. Our results therefore reconcile the finding in Longstaff, Mithal, and Neis (2005) that bonds issued by financial firms are more illiquid with the finding in Friewald, Jankowitsch, and Subrahmanyam (forthcoming) that there is no systematic liquidity difference.

\subsection{Liquidity betas}

We estimate bond-specific liquidity betas by calculating a monthly time series of corporate bond market illiquidity, and for each bond estimate the correlation between market-wide illiquidity and bond-specific illiquidity. The market-wide time series is calculated by averaging on a monthly basis across all observations of bond-specific $\lambda_{i}$ using amount outstanding as weight. Bond-specific beta is estimated through the slope coefficient in the regression of bond-specific $\lambda_{i}$ on market-wide $\lambda$, where the regression is based on all months where a bond-specific $\lambda_{i}$ can be calculated. We calculate the betas using the whole sample period 2005Q1-2009Q2, because estimating betas separately for the pre- and post-subprime periods leads to noisier estimates. Once we have estimated a liquidity beta using the complete sample period, we examine the dependence of spreads on this beta in the two subperiods.

For each rating class $R$, pooled regressions are run where yield spreads are regressed on each bond's liquidity $\beta$ and our liquidity measure $\lambda_{t}$ with credit risk controls:

Spread $_{i t}^{R}=\alpha^{R}+\gamma_{1}^{R} \lambda_{i t}+\gamma_{2}^{R} \beta_{i}+$ Credit risk controls ${ }_{i t}+\epsilon_{i t}$,

where $i$ is for bond in rating $R$ and $t$ is time measured in quarters.

The result of the regression is reported in Table 6. Our regressions are run both 'marginally', i.e., with the liquidity beta as the only regressor in addition to the credit risk controls, and with our liquidity measure included as an additional regressor.

Both marginally and with $\lambda$ included, there is no significance pre-subprime except for the AAA-category. After the onset of the crisis, the picture changes and only spreads in the AAA-category do not depend on the liquidity beta. This is consistent with the regime-dependent importance of liquidity betas noted in Acharya, Amihud, and Bharath (2010). But whereas they use stock and Treasury bond market liquidity to measure aggregate liquidity, our measure specifically captures corporate bond market liquidity.

We saw in the previous section that the contribution to spreads of liquidity was small for AAA bonds after the 


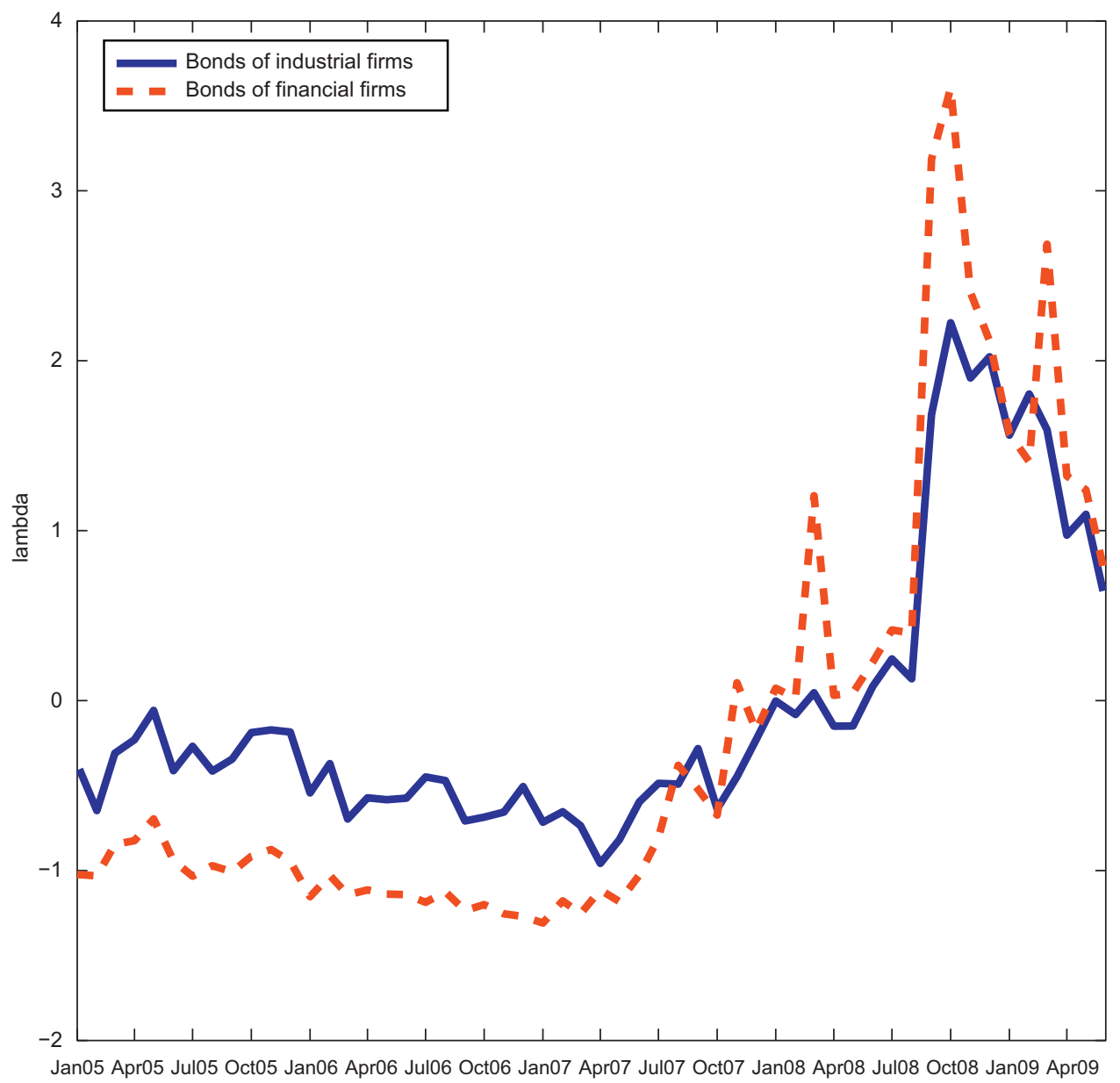

Fig. 5. Illiquidity of bonds of industrial and financial firms. This graph shows the time-series variation in illiquidity of bonds of industrial and financial firms. The data are U.S. corporate bond transactions from TRACE and the sample period is from 2005:Q1 to 2009:Q2. For every bond issued by a financial firm, their (il)liquidity measure $\lambda$ is calculated each month and a monthly weighted average is calculated using amount outstanding for each bond as weight. The graph shows the time series of monthly averages. Likewise, a time series of monthly averages is calculated for bonds issued by industrial firms. Higher values on the $y$-axis imply more illiquid bonds.

onset of the crisis, and the insignificant liquidity beta coefficient for AAA in the crisis period confirms that there is a flight-to-quality effect in AAA-rated bonds.

\section{Robustness checks}

In Appendix B we carry out a series of robustness checks. We test for potential endogeneity bias and find that endogeneity is not a major concern. We calculate liquidity premia using corporate bond spreads to Treasury rates instead of swap rates and find that our conclusions still hold. And we examine an alternative definition of our liquidity component and find results to be robust to this definition.

As a further test showing that our regression results are robust, we employ a different methodology for controlling for credit risk. The idea is that any yield spread difference between two fixed-rate bullet bonds with the same maturity and issued by the same firm must be due to liquidity differences and not differences in credit risk. This intuition is formalized in the following regression. We conduct rating-wise 'paired' regressions of yield spreads on dummy variables and one liquidity measure at a time. The regression is

$$
\text { Spread }_{i t}^{R}=\text { Dummy }_{G t}^{R}+\beta^{R} \lambda_{i t}+\epsilon_{i t},
$$

where Dummy $y_{G t}^{R}$ is the same for all bonds with the same rating $R$ and approximately the same maturity. The grid of maturities is $0-0.5 y, 0.5-1 \mathrm{y}, 1-3 \mathrm{y}, 3-5 \mathrm{y}, 5-7 \mathrm{y}, 7-10 \mathrm{y}$, and more than $10 \mathrm{y}$. For example, if firm $i$ in quarter $t$ has three bonds issued with maturities $5 \mathrm{y}, 5.5 \mathrm{y}$, and $6 \mathrm{y}$, the bonds have the same dummy in that quarter, and we assume that any yield spread difference between the bonds is due to liquidity. There are separate dummies for each quarter. Once we have dummied out credit risk in the regressions, estimated coefficients for the liquidity measure are not inconsistent because of possibly omitted credit risk variables. Hence, the paired regression is free of any endogeneity bias due to credit risk. Only groups with two or more spreads contribute to the liquidity coefficient reducing the sample compared to former regressions. Therefore, we only look at two rating groups, investment grade and speculative grade. Table 7 shows the regression 
Table 6

Beta regressions.

For each rating class $R$, pooled regressions are run where yield spreads are regressed on each bond's liquidity $\beta$ and our liquidity measure $\lambda_{t}$ with credit risk controls:

$$
\text { Spread }_{i t}^{R}=\alpha^{R}+\gamma_{1}^{R} \lambda_{i t}+\gamma_{2}^{R} \beta_{i}+\text { Credit risk controls } s_{i t}+\epsilon_{i t},
$$

where $i$ is for bond in rating $R$ and $t$ is time measured in quarter. Each bond's $\beta_{i}$ is calculated as the covariance between this bond's monthly $\lambda_{i t}$ and a size-weighted monthly market $\lambda_{M t}$. Two regressions for each rating pre- and post-subprime are run; one with only $\beta$ included and one with both $\beta$ and $\lambda$ included. The pre-subprime period is 2005:Q1-2007:Q1 while the post-subprime period is 2007:Q2-2009:Q2. The data are U.S. corporate bond transactions from TRACE. Standard errors are corrected for timeseries effects, firm fixed effects, and heteroskedasticity, and significance at $10 \%$ level is marked *, at $5 \%$ marked $* *$, and at $1 \%$ marked ****

\begin{tabular}{|c|c|c|c|c|}
\hline & \multicolumn{2}{|c|}{ Pre-subprime } & \multicolumn{2}{|c|}{ Post-subprime } \\
\hline & $\beta$ & $\lambda$ & $\beta$ & $\lambda$ \\
\hline \multirow[t]{2}{*}{ AAA } & $\underset{(-1.34)}{-0.0034}$ & & $\underset{(-0.84)}{-0.0085}$ & \\
\hline & $-0.0056^{* * * *}$ & $0.0033_{(2.65)}^{* * *}$ & $\underset{(1.26)}{0.0159}$ & $\underbrace{0.0234^{* * *}}_{(2.38)}$ \\
\hline \multirow[t]{2}{*}{ AA } & $\underset{(0.23)}{0.0012}$ & & $0.1823^{*}$ & \\
\hline & $\underset{(1.06)}{0.0067}$ & $\underset{(0.60)}{0.0017}$ & $0.1720^{\text {**** }}$ & $0.1712_{(3.82)}^{\text {***** }}$ \\
\hline \multirow[t]{2}{*}{ A } & $\underset{(-0.14)}{-0.0004}$ & & $0.2631^{\text {*** }}$ & \\
\hline & $\underset{(0.65)}{0.0021}$ & $\underset{(2.57)}{0.0106^{* * *}}$ & $\begin{array}{c}0.2314^{* * *} \\
(2.15)\end{array}$ & $0.1211_{(2.03)}^{* *}$ \\
\hline \multirow[t]{2}{*}{ BBB } & $\underset{(1.34)}{0.0044}$ & & $0.2171_{(4.05)}^{* * *}$ & \\
\hline & $\underset{(0.34)}{0.0012}$ & $\underset{(4.33)}{0.0254^{* * * *}}$ & $0.3187^{* * * *}$ & $0.3242^{*}$ (2.91) \\
\hline \multirow[t]{2}{*}{ Spec } & $\underset{(0.90)}{0.0102}$ & & $\begin{array}{c}1.3538^{* * * * * *} \\
(2.60)\end{array}$ & \\
\hline & $\underset{(1.31)}{0.0162}$ & $0.1502_{(4.64)}^{* * *}$ & $\frac{1.3140^{* * *}}{(2.73)}$ & $\begin{array}{c}0.4155^{* * * * *} \\
(7.08)\end{array}$ \\
\hline
\end{tabular}

\section{Table 7}

Paired regression.

We pair bonds from the same firm with similar maturity and regress their yield spreads on liquidity variables one at a time and add a dummy for a given firm and maturity combination. Since bonds with similar maturity and issued by the same firm have similar credit risk characteristics, the dummy controls for credit risk. Significance at $10 \%$ level is marked *, at $5 \%$ marked $* *$, and at $1 \%$ marked $* * *$. The data are U.S. corporate bond transactions from TRACE and the sample period is from 2005:Q1 to 2009:Q2.

\begin{tabular}{|c|c|c|c|c|}
\hline & \multicolumn{2}{|c|}{ Pre-subprime } & \multicolumn{2}{|c|}{ Post-subprime } \\
\hline & Investment & Speculative & Investment & Speculative \\
\hline$\lambda$ & $0.01_{(3.79)}^{* * * *}$ & $0.0 .99^{\text {***k }}$ & $0.12^{* * * * *}$ & $\begin{array}{l}0.41^{*} \\
(1.95)\end{array}$ \\
\hline Amihud & $2.26^{* * * * *}$ & ${ }_{(3.51)}^{16.80^{* * * *}}$ & ${ }_{(3.04)}^{16.10^{* * * *}}$ & $\begin{array}{l}54.65 \\
(1.54)\end{array}$ \\
\hline Roll & ${ }_{(3.56)}^{0.03^{* * * * *}}$ & $0.16^{* * *}$ & $\begin{array}{c}0.05^{* *} \\
(2.14)\end{array}$ & $\begin{array}{l}0.39 \\
(1.44)\end{array}$ \\
\hline Bond zero & $\frac{0.00^{* *} * * *}{(5.85)}$ & $0.01^{* * *}$ & $\begin{array}{l}0.00 \\
(0.78)\end{array}$ & $\begin{array}{l}0.03 \\
(1.12)\end{array}$ \\
\hline Turnover & $\underset{(1.87)}{0.11^{*}}$ & ${ }_{(1.72)}^{1.48^{*}}$ & $\begin{array}{l}-3.21 \\
(-1.46)\end{array}$ & $\begin{array}{c}72.74 \\
(1.63)\end{array}$ \\
\hline IRC & $8.48^{* * * * *}$ & ${ }_{(2.55)}^{125.03^{* *}}$ & ${ }_{(2.43)}^{104.34 * *}$ & $\begin{array}{c}-95.04 \\
(-0.58)\end{array}$ \\
\hline IRC risk & $\begin{array}{l}1.30 \\
(0.69)\end{array}$ & ${ }_{(2.15)}^{57.15^{* * *}}$ & $\begin{array}{c}39.09^{* * * * * *} \\
(2.97)\end{array}$ & $\begin{array}{c}-103.42 \\
(-0.74)\end{array}$ \\
\hline Amihud risk & $0.64^{* * * * * *}$ & $\underset{(2.79)}{9.44^{* * * *}}$ & $\underset{(3.19)}{6.56^{* * * *}}$ & $\begin{array}{c}39.63^{* * * * * *} \\
4.60)\end{array}$ \\
\hline
\end{tabular}

coefficients in the paired regression. We see that $\lambda$ is significant for both investment grade and speculative grade bonds in the period before the subprime crisis as well as after the onset of the crisis. This supports our finding that $\lambda$ is successful at disentangling liquidity and credit risk.

To address the potential concern that our results are confounded by an increase of new issues towards the end of the sample period, we calculate the average age of the bonds in the sample on a monthly basis. We find no trend during the sample period which suggests that our results are not driven by an increase in bond issues (results are available on request). We also recalculate the total spread and liquidity premium in Fig. 3 using only bonds in existence by February 2005. ${ }^{13}$ The reduction in the sample leads to increased noise in our results. To make it clear how this noise affects our results, we redo the calculations in two different ways. Recall that for each bond, the fraction due to illiquidity is calculated as $\beta_{t}\left(\lambda_{i t}-\lambda_{5 t}\right) /$ Spread $_{i t}$, where $\beta_{t}$ is the liquidity regression coefficient in month $t, \lambda_{i t}$ is the bond-specific liquidity level in month $t$, Spread $_{i t}$ the bond-specific spread, and $\lambda_{5 t}$ is the $5 \%$ liquidity quantile in month $t$. In the first recalculation, we assume that the sensitivities of spreads to illiquidity are not influenced by a potential issuance effect, but that the overall level of illiquidity might be effected. Specifically, we use the regression coefficients $\beta_{t}$ obtained using the full

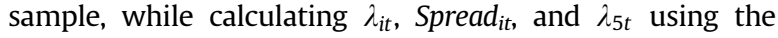
reduced sample (bonds in existence by February 2005). Fig. 6 shows the results along with those in Fig. 3 ('results in the paper', respectively, 'reduced sample, fixed reg. coeff.'). There is little difference in the results, so results based on $\lambda$ are robust to using only bonds issued by February 2005. In particular, this implies that our results on underwriter and financial vs. industrial firms are robust to a possible issuance effect. In our second recalculation, we also recalculate the regression coefficients $\beta_{t}$ using only bonds in existence by February 2005 . That is, we redo the whole analysis with the reduced sample. The results are also in Fig. 6 marked 'reduced sample'. (Note that the yield spreads are the same for the 'reduced sample, fixed reg. coeff.' and 'reduced sample' methods.) We see that results become more noisy, in particular for speculative grade bonds. For example, the liquidity component for speculative grade bonds in November 2008 is small. However, the results still show that the spike and subsequent decline in high yield spreads to a certain extent was a liquidity issue.

\section{Conclusion}

The subprime crisis dramatically increased corporate bond spreads and it is widely believed that deteriorating liquidity contributed to the widening of spreads.

We use a new measure of illiquidity-derived from a principal component analysis of eight liquidity proxies-to analyze the contribution of illiquidity to corporate bond spreads. The measure outperforms the Roll measure used in Bao, Pan, and Wang (2011) and zero-trading days used in Chen, Lesmond, and Wei (2007) in explaining spread variation. In fact, the number of zero-trading days tends to

\footnotetext{
${ }^{13}$ We thank the referee for this suggestion
} 
Investment grade

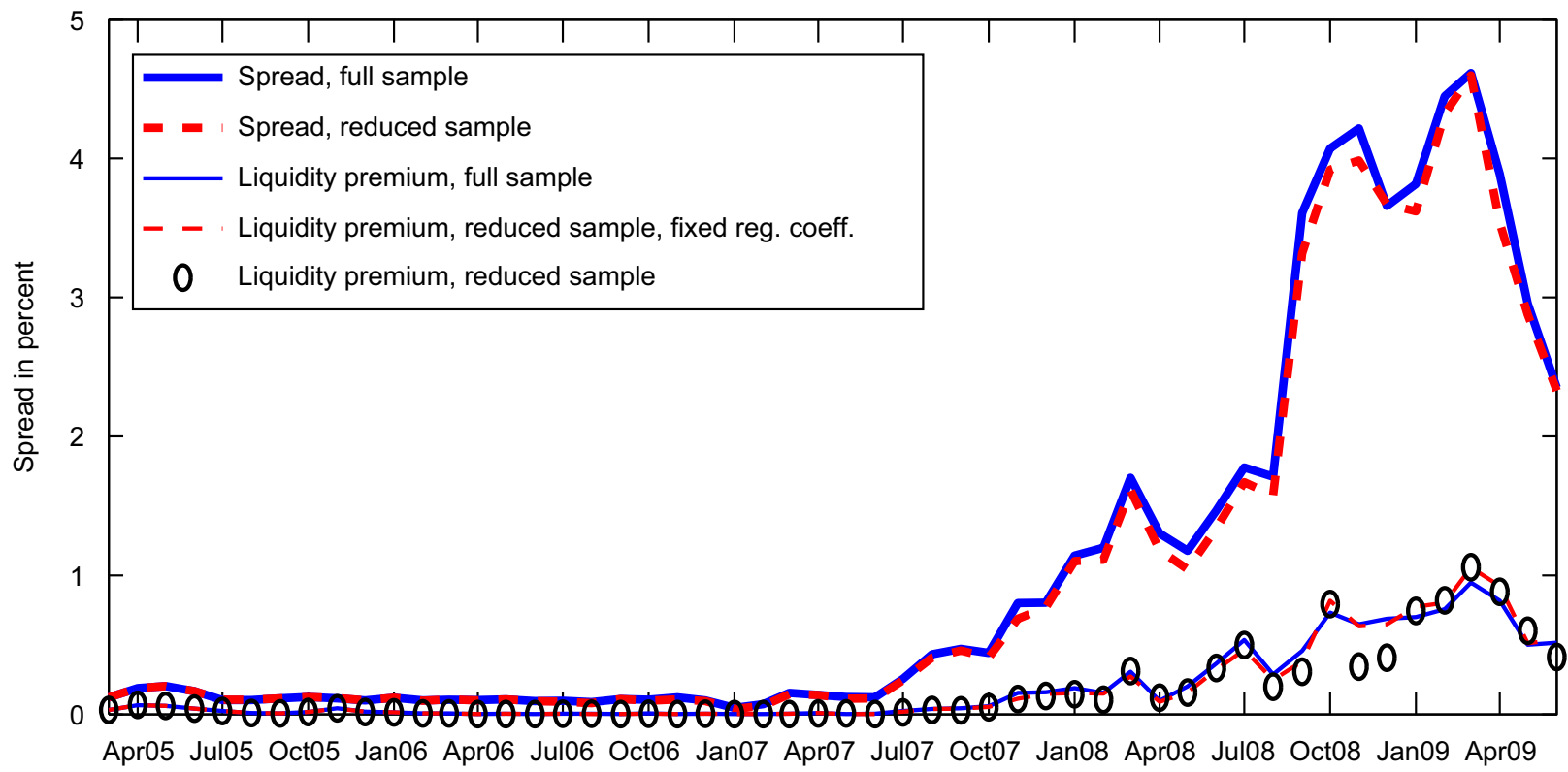

Speculative grade

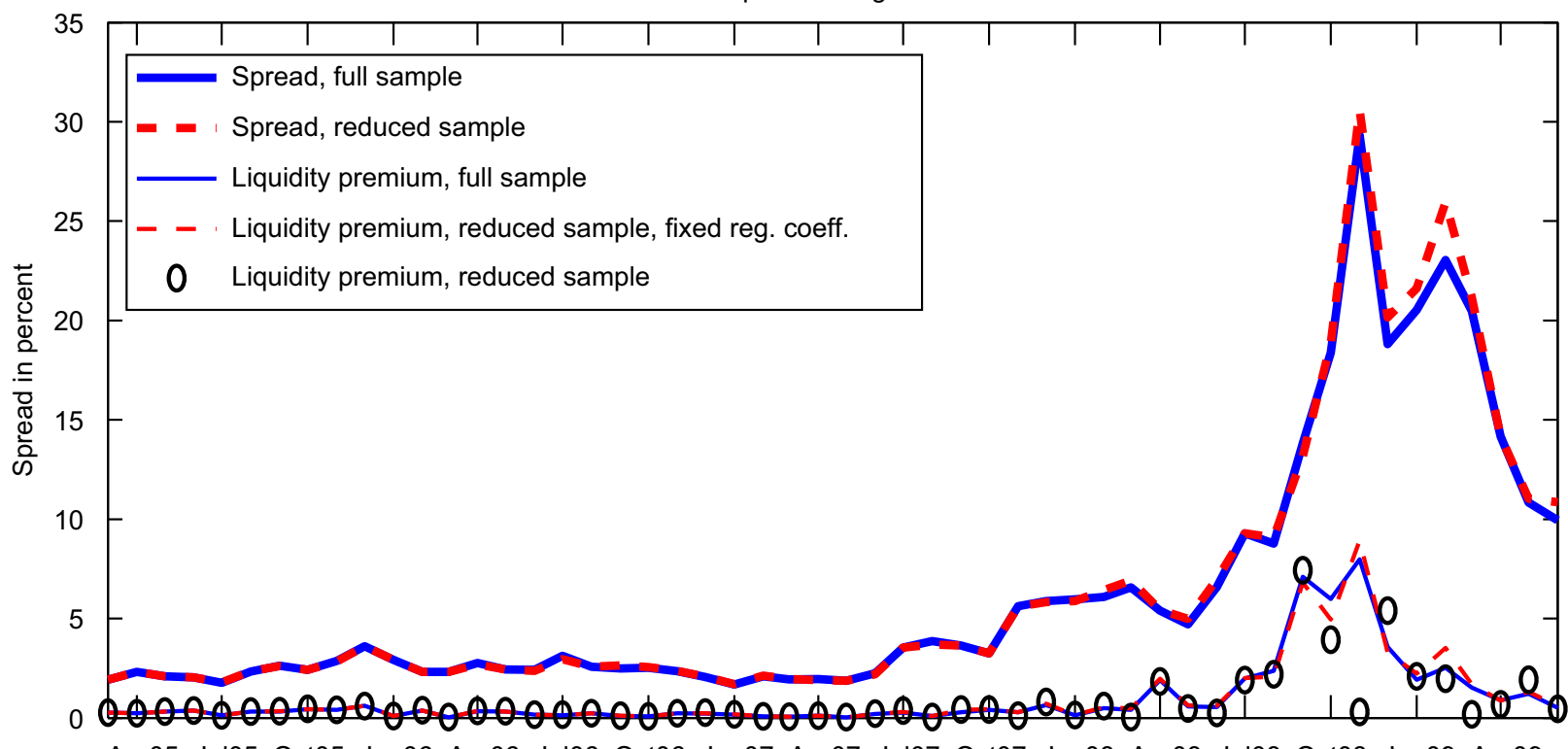

Apr05 Jul05 Oct05 Jan06 Apr06 Jul06 Oct06 Jan07 Apr07 Jul07 Oct07 Jan08 Apr08 Jul08 Oct08 Jan09 Apr09

Fig. 6. Liquidity premium and total spread for investment grade and speculative grade bonds using only bonds in existence by February 2005 . On a monthly basis, the fraction of the yield spread that is due to illiquidity is calculated as $\beta_{t}\left(\lambda_{i t}-\lambda_{5 t}\right) / \operatorname{Spread}_{i t}($ as explained in Section 4.3 . This fraction multiplied by the median yield spread is the amount of the spread due to illiquidity and plotted along with the median yield spread. 'Full sample' refers to the results in Fig. 3. 'Reduced sample' refers to results using a sample restricted to bonds in existence by February 2005 . 'Reduced sample, fixed reg. coeff.' refers to results where $\beta_{t}$ is calculated using the full sample while $\lambda_{i t}-\lambda_{5 t}$ is calculated using the reduced sample. The data are U.S. corporate bond transactions from TRACE and the sample period is from 2005:Q1 to 2009:Q2.

decrease during the crisis, because trades in less liquid bonds are split into trades of smaller size.

Before the crisis, the contribution to spreads was small for investment grade bonds both measured in basis points and as a fraction of total spreads. The contribution increased strongly at the onset of the crisis for all bonds except AAA-rated bonds, which is consistent with a flightto-quality into AAA-rated bonds. Liquidity premia in investment grade bonds rose steadily during the crisis and peaked when the stock market declined strongly in the first quarter of 2009, while premia in speculative grade bonds peaked during the Lehman default and returned almost to pre-crisis levels in mid-2009.

Our measure is useful for analyzing other aspects of corporate bond liquidity. We show that the financial distress of Lehman and Bear Stearns diminished the 
liquidity of the bonds for which they served as lead underwriters. We also compare the liquidity of bonds issued by financial firms with that of bonds issued by industrial firms. Bonds issued by financial firms have spikes of illiquidity around the take-over of Bear Stearns, the collapse of Lehman, and the March 2009 rapid stock market decline.

From the covariation between an individual bond's liquidity and market-wide liquidity, we define a measure of systematic illiquidity. This measure is shown to have little effect on spreads before the onset of the crisis, but it has a positive effect for all but AAA-rated bonds after the onset of the crisis. This is consistent with the regime-dependent role of liquidity betas found in Acharya, Amihud, and Bharath (2010), but it refines their flight-to-quality finding from general investment grade to AAA-rated bonds only.

\section{Appendix A. Implementation details}

In this appendix we describe in detail the implementation of the individual liquidity measures used in the main text and how we calculate corporate bond spreads. We winsorize the $0.5 \%$ highest values of every liquidity variable, meaning that all values above the $99.5 \%$ percentile are set to the $99.5 \%$ percentile. For corporate bond spreads we winsorize the $0.5 \%$ highest and lowest spreads as explained below.

\section{A.1. Corporate bond spreads}

We calculate the quarter-end yield as the average yield for all trades on the last day in the quarter where the bond traded. If a bond did not trade during the last month of the quarter, it is excluded from that quarter. Yield spreads are calculated as the difference between the bond yield and the interpolated maturity-matched swap rate calculated on the same day as the yield is measured. We exclude yield spreads for bonds that have less than one month to maturity or have a time to maturity when issued of more than 30 years. We winsorize the $0.5 \%$ highest and lowest spreads, so all spreads above the $99.5 \%$ percentile are set to the $99.5 \%$ percentile and all spreads below the $0.5 \%$ percentile are set to the $0.5 \%$ percentile.

\section{A.2. Amihud measure}

Amihud (2002) constructs an illiquidity measure based on the theoretical model of Kyle (1985) and we use a slightly modified version of this measure. It measures the price impact of a trade per unit traded. For each corporate bond, the measure is the daily average of absolute returns $r_{j}$ divided by the trade size $Q_{j}$ (in million $\$$ ) of consecutive transactions:

Amihud $_{t}=\frac{1}{N_{t}} \sum_{j=1}^{N_{t}} \frac{\left|r_{j}\right|}{Q_{j}}=\frac{1}{N_{t}} \sum_{j=1}^{N_{t}} \frac{\left|\frac{P_{j}-P_{j-1}}{P_{j-1}}\right|}{Q_{j}}$,

where $N_{t}$ is the number of returns on day $t$. At least two transactions are required on a given day to calculate the measure, and we define a quarterly Amihud measure by taking the median of daily measures within the quarter.

\section{A.3. Roll measure}

Roll (1984) finds that under certain assumptions, the percentage bid-ask spread equals two times the square root of minus the covariance between consecutive returns:

$\operatorname{Roll}_{t}=2 \sqrt{-\operatorname{Cov}\left(R_{i}, R_{i-1}\right)}$,

where $t$ is the time period for which the measure is calculated. If the covariance is negative, the observation is discarded. The intuition is that the bond price bounces back and forth between the bid and the ask price, and higher percentage bid-ask spreads lead to higher negative covariance between consecutive returns. We define a daily Roll measure on days with at least one transaction using a rolling window of 21 trading days, and the measure is only well-defined if there are at least four transactions in the window. We define a quarterly Roll measure by taking the median of daily measures within the quarter.

\section{A.4. Imputed roundtrip cost}

Feldhütter (in press) proposes an alternative measure of transaction costs based on what he calls Imputed Roundtrip Trades. The intuition is the following. Often, we see a corporate bond trading two or three times within a very short period of time after a longer period with no trades. This is likely to occur because a dealer matches a buyer and a seller and collects the bid-ask spread as a fee. When the dealer has found a match, a trade between seller and dealer along with a trade between buyer and dealer are carried out. Possibly, the matching occurs through a second dealer in which case there is also a transaction between the two dealers. If two or three trades in a given bond with the same trade size take place on the same day, and there are no other trades with the same size on that day, we define the transactions as part of an IRT. For an IRT we define the imputed roundtrip cost (IRC) as

$\frac{P_{\max }-P_{\min }}{P_{\max }}$,

where $P_{\max }$ is the largest price in the IRT and $P_{\min }$ is the smallest price in the IRT. A daily estimate of roundtrip costs is the average of roundtrip costs on that day for different trade sizes, and we estimate quarterly roundtrip costs by averaging over daily estimates. Feldhütter (in press) examines the properties of IRTs in detail, including how much of total trading volume is captured, and for a subsample of TRACE data with buy-sell indicators available, to what extent IRTs capture full roundtrip costs.

\section{A.5. Turnover}

We also consider the quarterly turnover of bonds:

Turnover $_{t}=\frac{\text { Total trading volume }_{t}}{\text { Amount outstanding }}$,

where $t$ is the quarter. We can interpret the inverse of the turnover as the average holding time of the bond, i.e., 
a turnover of one implies an average holding time of about three months.

\section{A.6. Zero trading days}

We calculate bond zero-trading days as the percentage of days during a quarter where the bond did not trade. We also calculate firm zero-trading days as the percentage of days during a quarter where none of the issuing firm's bonds traded. Clearly, this is a firm-specific rather than a bond-specific measure, and it is therefore the same for different bonds issued by the same firm.

\section{A.7. Variability of Amihud and imputed roundtrip costs}

It is likely that investors consider not only the current level of bond liquidity but also the possible future levels in case the investor needs to sell the bond. The variability of both the Amihud measure and imputed roundtrip costs may therefore play a role for liquidity spreads. Thus, we include in our regressions the standard deviations of the daily Amihud measure and imputed roundtrip costs measured over one-quarter.

\section{A.8. The measure $\lambda$}

As described in the main text, a principal component analysis of the liquidity measures leads us to define a factor that loads evenly on Amihud, IRC, Amihud risk, and IRC risk. We call this measure $\lambda$. To be precise: for each bond $i$ and quarter $t$ we calculate the measure $L_{i t}^{j}$, where $j=1, \ldots, 4$ is an index for Amihud, IRC, Amihud risk, and IRC risk. We normalize each measure $\tilde{L}_{i t}^{j}=\left(L_{i t}^{j}-\mu^{j}\right) / \sigma^{j}$, where $\mu^{j}$ and $\sigma^{j}$ are the mean and standard deviation of $L^{j}$ across bonds and quarters and define our liquidity measure for each bond and quarter as

$\lambda_{i t}=\sum_{j=1}^{4} \tilde{L}_{i t}^{j}$.

\section{Appendix B. Robustness checks}

In this appendix we discuss possible misspecification in our regression analysis. We test for endogeneity, show that our results are robust to the choice of benchmark riskfree rate, and show that results are robust to how we define the liquidity component. Finally, we show that only the first principal component of the eight liquidity proxies consistently predicts yield spreads.

\section{B.1. Endogeneity}

There may be a two-way causal relationship between contemporaneous measures of liquidity and credit risk, and failing to account for such a relationship in regressions results in inconsistent OLS estimates. Our liquidity measures are lagged in time relative to credit spreads, since spreads are measured on the last day in each quarter while liquidity measures are based on transactions during the quarter. Therefore, simultaneity bias is not a concern.
Table B1

Endogeneity tests.

For each rating class $R$ and each liquidity variable $L$, we test for potential endogeneity bias by using a Durbin-Wu-Hausman test. In total, 45 tests are run (nine liquidity variables $\times$ five rating classes) pre- and post-subprime. This table shows for each test the $t$-statistics and $R^{2}$ for the first-stage regression in parentheses. The data are U.S. corporate bond transactions from TRACE and the sample period is from 2005:Q1 to 2009:Q2. Panel A shows the coefficients using data before the subprime crisis, while Panel B shows the coefficients using data after the onset of the subprime crisis. Significance at $10 \%$ level is marked ${ }^{*}$, at $5 \%$ marked $* *$, and at $1 \%$ marked ***.

Panel A: Endogeneity tests, pre-subprime (2005:Q1-2007:Q1)

\begin{tabular}{lccccc}
\hline & AAA & AA & A & BBB & Spec \\
$\lambda$ & 0.55 & -1.06 & 0.96 & 1.50 & 0.61 \\
\multirow{2}{*}{ Amihud } & $(28 \%)$ & $(16 \%)$ & $(17 \%)$ & $(19 \%)$ & $(40 \%)$ \\
\multirow{2}{*}{ Roll } & -0.43 & -1.00 & 0.98 & 1.31 & 0.71 \\
& $(33 \%)$ & $(20 \%)$ & $(18 \%)$ & $(9 \%)$ & $(34 \%)$ \\
Firm zero & 0.66 & -0.98 & 0.98 & 1.16 & -0.45 \\
\multirow{2}{*}{ Bond zero } & $-(47 \%)$ & $(30 \%)$ & $(32 \%)$ & $(24 \%)$ & $(25 \%)$ \\
& -0.25 & 1.08 & -0.83 & -1.18 & 0.27 \\
Turnover & $-0.41 \%$ & $(34 \%)$ & $(23 \%)$ & $(25 \%)$ & $(46 \%)$ \\
& $(83 \%)$ & 1.04 & -0.69 & 0.85 & -0.87 \\
IRC & -0.18 & -1.13 & 0.86 & -1.05 & $(61 \%)$ \\
& $(19 \%)$ & $(28 \%)$ & $(15 \%)$ & $(29 \%)$ & $(39 \%)$ \\
Amihud risk & 0.51 & -1.08 & 0.95 & 1.45 & 0.13 \\
& $(34 \%)$ & $(18 \%)$ & $(19 \%)$ & $(23 \%)$ & $(37 \%)$ \\
IRC risk & 0.45 & -1.09 & 0.89 & 1.43 & 0.31 \\
& $(19 \%)$ & $(10 \%)$ & $(11 \%)$ & $(13 \%)$ & $(31 \%)$ \\
& 0.46 & -1.08 & 0.90 & 1.29 & -0.03 \\
& $(13 \%)$ & $(12 \%)$ & $(11 \%)$ & $(14 \%)$ & $(33 \%)$
\end{tabular}

Panel B: Endogeneity tests, post-subprime (2007:Q2-2009:Q2)

\begin{tabular}{|c|c|c|c|c|c|}
\hline & AAA & AA & A & BBB & Spec \\
\hline$\lambda$ & $-{ }_{(48 \%)}^{4.56 \% * *}$ & $\frac{-0.82}{(42 \%)}$ & $\begin{array}{c}-0.73 \\
\left(52^{\circ} \%\right)\end{array}$ & $\frac{-0.42}{\left(47^{\circ} \%\right)}$ & $-{ }_{(63 \%)}^{2.76^{* * * * * *}}$ \\
\hline Amihud & $-{ }_{(41 \%)}^{5.03^{* * * * *}}$ & $\begin{array}{c}-1.06 \\
(31 \%)\end{array}$ & $\begin{array}{l}-0.20 \\
(30 \%)\end{array}$ & $\begin{array}{c}-0.60 \\
(27 \%)\end{array}$ & $-\underset{(42 \%)}{2.82^{* * * * * *}}$ \\
\hline Roll & $-\underbrace{5.24^{* * * *}}_{(33 \%)}$ & $\frac{-1.15}{(15 \%)}$ & $\begin{array}{l}0.51 \\
(21 \%)\end{array}$ & $\underset{(16 \%)}{0.77}$ & $-\underbrace{2.89}_{(23 \%)}$ \\
\hline Firm zero & $5.50_{(87 \%)}^{* * * * *}$ & $\frac{-1.12}{(35 \%)}$ & $\underset{\left(24^{\circ} \%\right)}{-0.40}$ & $\frac{-0.82}{(44 \%)}$ & $-{ }_{(58 \%)}^{3.06^{* * * * *}}$ \\
\hline Bond zero & $\frac{6.40^{* * * * *}}{(79 \%)}$ & 1.10 & $\begin{array}{c}-0.21 \\
(70 \%)\end{array}$ & $\frac{-0.70}{(68 \%)}$ & $-3.26^{* * * * * *}$ \\
\hline Turnover & $-\underbrace{6.17^{* * * *}}_{(27 \%)}$ & $\frac{-1.15}{\left(16^{\circ} \%\right)}$ & $\begin{array}{l}0.32 \\
\left(17^{\circ} \%\right)\end{array}$ & $\begin{array}{l}0.73 \\
(20 \%)\end{array}$ & $\underset{(36 \%)}{2.91^{* * * * *}}$ \\
\hline IRC & $-{ }_{(50 \%)}^{4.94^{* * * *}}$ & $\begin{array}{c}-0.84 \\
(42 \%)\end{array}$ & $\begin{array}{l}-0.26 \\
(49 \%)\end{array}$ & $\begin{array}{l}0.77 \\
(39 \%)\end{array}$ & $-{ }_{(63 \%)}^{2.72^{* * * * *}}$ \\
\hline Amihud risk & $-{ }_{(21 \%)}^{5.07^{* * * *}}$ & $\begin{array}{l}-1.05 \\
(22 \%)\end{array}$ & $\begin{array}{c}-0.36 \\
(34 \%)\end{array}$ & $\begin{array}{c}-0.59 \\
(45 \%)\end{array}$ & $-{ }_{(50 \%)}^{2.69 * * * *}$ \\
\hline IRC risk & $-{ }_{(39 \%)}^{4.82 * * *}$ & $\begin{array}{c}-0.74 \\
(34 \%)\end{array}$ & $\begin{array}{l}0.57 \\
(48 \%)\end{array}$ & $\frac{-0.75}{(34 \%)}$ & $-{ }_{(55 \%)}^{2.75 * * * * *}$ \\
\hline
\end{tabular}

To test for potential endogeneity bias, we use a residual augmented two-stage least squares $t$-test as in Davidson and MacKinnon (1993), equivalent to the Durbin-Wu-Hausman test. We do this for every marginal regression in Table 3, that is, test every liquidity variable separately. If the test is not significant, the liquidity variable can be regarded as exogenous. As instrument we use bond age and therefore exclude it in the yield spread regressions. ${ }^{14}$ Table B1 shows the $R^{2 \text { s }}$ for the first stage regressions and the $t$-statistic tests for endogeneity. Most $R^{2}$ 's are relatively high indicating that the control variables including the instrument are able to explain a large portion of the variation in the liquidity measures. Out

\footnotetext{
${ }^{14}$ Another potential instrument is amount issued. Since this variable is significant in most of the regressions in Table B4, omitting it from the regressions in the test creates a new endogeneity problem. The tests in this case would likely show an endogeneity problem even if it is not there; and if we use amount issued as instrument, this is indeed the case.
} 
Table B2

Liquidity component in basis points when the Treasury rate is used as riskfree rate.

For each rating $R$, we run the pooled regression

$$
\text { Spread }_{i t}^{R}=\alpha^{R}+\beta^{R} \lambda_{i t}+\text { Credit risk controls }{ }_{i t}+\epsilon_{i t},
$$

where $i$ refers to bond, $t$ to time, and $\lambda_{i t}$ is our liquidity measure. The bond spread is measured with respect to the Treasury yield. Within each rating and maturity bucket $(0-2 y, 2-5 y$, and $5-30 y)$, we sort increasingly all values of $\lambda_{i t}$ and find the median value $\lambda_{50}$ and the $5 \%$ value $\lambda_{5}$. The liquidity component in the bucket is defined as $\beta\left(\lambda_{50}-\lambda_{5}\right)$. This table shows for all buckets the liquidity component with standard errors in parentheses. The data are U.S. corporate bond transactions from TRACE and the sample period is from 2005:Q1 to 2009:Q2. Confidence bands are found by a wild cluster bootstrap.

Panel A: Liquidity component in basis points, pre-subprime (2005Q1-2007:Q1)

\begin{tabular}{|c|c|c|c|c|c|c|c|}
\hline & \multirow[t]{2}{*}{ Average } & \multicolumn{3}{|c|}{ Liquidity component, basis points } & \multicolumn{3}{|c|}{ Number of observations } \\
\hline & & $0-2 y$ & $2-5 y$ & $5-30 y$ & $0-2 y$ & $2-5 y$ & $5-30 y$ \\
\hline AAA & 1.6 & $\begin{array}{ll}1.1 \\
(0.8 ; 1.4)\end{array}$ & $\begin{array}{ll}1.7 \\
(1.2 ; 2.1)\end{array}$ & $\underset{(1.4 ; 2.5)}{2.0}$ & 162 & 178 & 193 \\
\hline $\mathrm{AA}$ & 1.7 & $\begin{array}{c}1.1 \\
(0.8 ; 1.5)\end{array}$ & $\begin{array}{c}1.8 \\
(1.3 ; 2.3)\end{array}$ & $\begin{array}{l}2.3 \\
(1.6 ; 3.0)\end{array}$ & 704 & 667 & 498 \\
\hline A & 2.8 & $\begin{array}{c}1.7 \\
(0.9 ; 2.6)\end{array}$ & $\begin{array}{c}2.9 \\
(1.5 ; 4.3)\end{array}$ & $\begin{array}{c}3.8 \\
(1.9 ; 5.5)\end{array}$ & 1540 & 1346 & 1260 \\
\hline BBB & 4.0 & $\begin{array}{c}2.9 \\
(1.4 ; 4.4)\end{array}$ & $\begin{array}{c}4.1 \\
(1.9 ; 6.2)\end{array}$ & $\begin{array}{c}4.9 \\
(2.3 ; 7.3)\end{array}$ & 517 & 270 & 553 \\
\hline Spec & 57.8 & $\begin{array}{c}45.2 \\
(33.9 ; 57.4)\end{array}$ & $\begin{array}{c}44.1 \\
(33.1 ; 56.0)\end{array}$ & $\begin{array}{c}84.2 \\
(63.2 ; 106.9)\end{array}$ & 270 & 324 & 480 \\
\hline
\end{tabular}

Panel B: Liquidity component in basis points, post-subprime (2007:Q2-2009:Q2)

\begin{tabular}{|c|c|c|c|c|c|c|c|}
\hline & \multirow[t]{2}{*}{ Average } & \multicolumn{3}{|c|}{ Liquidity component, basis points } & \multicolumn{3}{|c|}{ Number of observations } \\
\hline & & $0-2 y$ & $2-5 y$ & $5-30 y$ & $0-2 y$ & $2-5 y$ & $5-30 y$ \\
\hline AAA & 1.0 & $\begin{array}{c}0.5 \\
(0.3 ; 5.4)\end{array}$ & $\begin{array}{c}0.8 \\
(0.5 ; 8.1)\end{array}$ & $\begin{array}{c}1.7 \\
(0.9 ; 16.6)\end{array}$ & 110 & 149 & 155 \\
\hline AA & 40.6 & $\begin{array}{c}22.9 \\
(11.5 ; 35.2)\end{array}$ & $\begin{array}{c}36.1 \\
(18.2 ; 55.5)\end{array}$ & $\begin{array}{c}63.0 \\
(31.8 ; 96.8)\end{array}$ & 493 & 572 & 483 \\
\hline A & 47.6 & $\begin{array}{c}25.0 \\
(12.9 ; 37.6)\end{array}$ & $\begin{array}{c}47.9 \\
(24.7 ; 72.1)\end{array}$ & $\begin{array}{c}70.0 \\
(36.1 ; 105.4)\end{array}$ & 762 & 878 & 890 \\
\hline BBB & 94.0 & $\begin{array}{c}65.2 \\
(36.0 ; 97.4)\end{array}$ & $\begin{array}{c}117.2 \\
(64.8 ; 175.1)\end{array}$ & $\begin{array}{c}99.5 \\
(55.0 ; 148.6)\end{array}$ & 123 & 159 & 256 \\
\hline Spec & 189.9 & $\begin{array}{c}119.3 \\
(79.4 ; 154.9)\end{array}$ & $\begin{array}{l}216.3 \\
(144.0 ; 280.9)\end{array}$ & $\begin{array}{c}234.2 \\
(156.0 ; 304.2)\end{array}$ & 133 & 129 & 201 \\
\hline
\end{tabular}

of the 90 test statistics, $80 \%$ are insignificant at a $10 \%$ level indicating that endogeneity is not a major concern.

\section{B.2. Benchmark riskfree rate}

The size of the nondefault component in corporate bond spreads investigated by, among others, Huang and Huang (2003) and Longstaff, Mithal, and Neis (2005), depends strongly on the chosen riskfree rate. In Longstaff, Mithal, and Neis (2005) the difference is around 60bp. As Table B2 shows, the estimated liquidity component when the Treasury rate is used as riskfree rate instead of the swap rate does not change much. The change in estimated liquidity is often less than $1 \mathrm{bp}$ and is for all rating categories less than 10bp. Therefore, our findings on the size of the liquidity premium in basis points are insensitive to the choice of benchmark (while our findings on the fraction out of the total spread of course depend on the benchmark riskfree rate).

\section{B.3. Alternative definition of liquidity component}

The liquidity component is calculated as the median minus 5\% quantile of the liquidity score and has the natural interpretation as the liquidity premium of an average bond in the corporate bond market relative to a very liquid bond. To check that our main results are robust to the definition of the liquidity component, Table B3 shows the liquidity component when it is defined as the $75 \%$ quantile minus $5 \%$ quantile. The component in this table can be interpreted as that of an illiquid bond relative to a very liquid bond. Table B3 shows that the liquidity component is larger for an illiquid bond compared to an average bond (which by definition must be the case). Also, Table B3 shows that the main results of the paper are unchanged: liquidity premia are increasing in maturity, the liquidity premium is higher post-subprime compared to pre-subprime, and the liquidity premium for investment grade bonds is small pre-subprime.

\section{B.4. Higher-order principal components}

In the main text we base our definition of $\lambda$ on the first principal component of eight liquidity proxies and argue that $\lambda$ is a more consistent proxy for liquidity compared to the individual measures. It might be the case that some of the other principal components contain important information about liquidity, so Table B4 shows the regression in Eq. (1) with all eight principal components included. ${ }^{15}$ For completeness, the coefficients of the credit risk controls are also shown in the table.

\footnotetext{
${ }^{15}$ It might be surprising that the regression coefficients for the first PC are very different from those for $\lambda$ in Table 3 . The reason is that the variance of the first principal component is equal to the first eigenvalue, while the variance of $\lambda$ is equal to one.
} 


\section{Table B3}

Liquidity component in basis points for an illiquid bond.

For each rating $R$, we run the pooled regression

$$
\text { Spread }_{i t}^{R}=\alpha^{R}+\beta^{R} \lambda_{i t}+\text { Credit risk controls }{ }_{i t}+\epsilon_{i t},
$$

where $i$ refers to bond, $t$ to time, and $\lambda_{i t}$ is our liquidity measure. The bond spread is measured with respect to the swap rate. Within each rating and maturity bucket $\left(0-2 y, 2-5 y\right.$, and $5-30 y$ ), we sort increasingly all values of $\lambda_{i t}$ and find the $75 \%$ value $\lambda_{75}$ and the $5 \%$ value $\lambda_{5}$. The liquidity component in the bucket is defined as $\beta\left(\lambda_{75}-\lambda_{5}\right)$. This table shows for all buckets the liquidity component with standard errors in parentheses. The data are U.S corporate bond transactions from TRACE and the sample period is from 2005:Q1 to 2009:Q2. Confidence bands are found by a wild cluster bootstrap.

Panel A: Liquidity component in basis points, pre-subprime (2005Q1-2007:Q1)

\begin{tabular}{|c|c|c|c|c|c|c|c|}
\hline & \multirow[t]{2}{*}{ Average } & \multicolumn{3}{|c|}{ Liquidity component, basis points } & \multicolumn{3}{|c|}{ Number of observations } \\
\hline & & $0-2 y$ & $2-5 y$ & $5-30 y$ & $0-2 y$ & $2-5 y$ & $5-30 y$ \\
\hline AAA & 1.4 & $\begin{array}{c}1.0 \\
(0.5 ; 1.3)\end{array}$ & $\begin{array}{c}1.2 \\
(0.7 ; 1.7)\end{array}$ & $\underset{(1.1 ; 2.8)}{2.0}$ & 162 & 178 & 193 \\
\hline AA & 1.7 & $\begin{array}{c}1.1 \\
(0.4 ; 1.7)\end{array}$ & $\begin{array}{c}1.6 \\
(0.6 ; 2.6)\end{array}$ & $\begin{array}{c}2.4 \\
(0.9 ; 3.8)\end{array}$ & 704 & 667 & 498 \\
\hline A & 4.4 & $\begin{array}{l}2.8 \\
(1.2 ; 4.3)\end{array}$ & $\begin{array}{c}4.3 \\
(1.8 ; 6.8)\end{array}$ & $\begin{array}{c}6.1 \\
(2.6 ; 9.6)\end{array}$ & 1540 & 1346 & 1260 \\
\hline BBB & 8.4 & $\begin{array}{c}5.8 \\
(2.4 ; 9.1)\end{array}$ & $\begin{array}{c}8.9 \\
(3.6 ; 13.9)\end{array}$ & $\begin{array}{c}10.4 \\
(4.2 ; 16.3)\end{array}$ & 517 & 270 & 553 \\
\hline Spec & 117.1 & $\begin{array}{c}81.5 \\
(61.2 ; 104.4)\end{array}$ & $\begin{array}{c}90.4 \\
(67.9 ; 115.8)\end{array}$ & $\begin{array}{c}179.4 \\
(134.6 ; 229.6)\end{array}$ & 270 & 324 & 480 \\
\hline
\end{tabular}

Panel B: Liquidity component in basis points, post-subprime (2007:Q2-2009:Q2)

\begin{tabular}{|c|c|c|c|c|c|c|c|}
\hline & \multirow[t]{2}{*}{ Average } & \multicolumn{3}{|c|}{ Liquidity component, basis points } & \multicolumn{3}{|c|}{ Number of observations } \\
\hline & & $0-2 y$ & $2-5 y$ & $5-30 y$ & $0-2 y$ & $2-5 y$ & $5-30 y$ \\
\hline AAA & 9.2 & $\begin{array}{l}4.4 \\
(0.9 ; 7.9)\end{array}$ & $\begin{array}{l}8.0 \\
(1.7 ; 14.2)\end{array}$ & $\begin{array}{l}15.2 \\
(3.2 ; 27.3)\end{array}$ & 110 & 149 & 155 \\
\hline AA & 68.5 & $\begin{array}{c}37.8 \\
(21.2 ; 53.4)\end{array}$ & $\begin{array}{c}64.0 \\
(35.8 ; 90.5)\end{array}$ & $\begin{array}{c}103.9 \\
(58.1 ; 146.9)\end{array}$ & 493 & 572 & 483 \\
\hline A & 92.6 & $\begin{array}{c}53.8 \\
(29.4 ; 78.8)\end{array}$ & $\begin{array}{c}95.9 \\
(52.5 ; 140.6)\end{array}$ & $\begin{array}{l}128.1 \\
(70.1 ; 187.7)\end{array}$ & 762 & 878 & 890 \\
\hline BBB & 176.5 & $\begin{array}{c}138.6 \\
(76.0 ; 203.3)\end{array}$ & $\begin{array}{c}201.6 \\
(110.5 ; 295.6)\end{array}$ & $\begin{array}{c}189.4 \\
(103.8 ; 277.8)\end{array}$ & 123 & 159 & 256 \\
\hline Spec & 420.5 & $\begin{array}{c}294.0 \\
(196.2 ; 383.0)\end{array}$ & $\begin{array}{c}390.5 \\
(260.6 ; 508.7)\end{array}$ & $\begin{array}{c}577.1 \\
(385.2 ; 751.8)\end{array}$ & 133 & 129 & 201 \\
\hline
\end{tabular}

\section{Table B4}

Liquidity regressions with eight liquidity PCs.

For each of the five rating classes, a pooled regression with quarterly observations is run with variables measuring both liquidity and credit risk. Panel A shows the regression coefficients and $t$-statistics in parentheses when using data from 2005:Q1 to 2007:Q1, while Panel B shows the results for data from 2007:Q2 to 2009:Q2. The data are U.S. corporate bond transactions from TRACE. Standard errors are corrected for time series effects, firm fixed effects, and heteroskedasticity, and significance at $10 \%$ level is marked *, at $5 \%$ marked $* *$, and at $1 \%$ marked $* * *$.

\begin{tabular}{|c|c|c|c|c|c|}
\hline \multicolumn{6}{|c|}{ Panel A: Pre-subprime (2005:Q1-2007:Q1) } \\
\hline & AAA & AA & A & BBB & Spec \\
\hline Intercept & $\begin{array}{l}-0.4 \\
(-1.24)\end{array}$ & $\begin{array}{c}0.2 \\
(1.20)\end{array}$ & $\begin{array}{l}-0.5 \\
(-1.62)\end{array}$ & $2.2_{(2.84)}^{* * * *}$ & $\begin{array}{l}-0.1 \\
(-0.03)\end{array}$ \\
\hline $1 \mathrm{PC}$ & $\underset{(3.22)}{0.01^{* * * * *}}$ & $0_{(12.31)}^{0.02 * * *}$ & $0.03^{* * 2 * *}$ & $0.05_{(2.88)}^{* * *}$ & $\underset{0.30 * \text { **** }}{(5.65)}$ \\
\hline $2 \mathrm{PC}$ & $\begin{array}{l}0.01 \\
(0.58)\end{array}$ & $\begin{array}{l}-0.00 \\
(-0.09)\end{array}$ & $0.04^{* * * * *}$ & $\begin{array}{l}-0.06 \\
(-1.30)\end{array}$ & $\begin{array}{l}-0.19 \\
(-1.19)\end{array}$ \\
\hline 3PC & $-0.014^{\text {****** }}$ & $\underset{(-0.72)}{-0.006}$ & $\frac{0.018^{* * * * k}}{(2.66)}$ & $\begin{array}{l}-0.005 \\
(-0.21)\end{array}$ & $\frac{0.093}{(0.88)}$ \\
\hline $4 \mathrm{PC}$ & $-0.020^{* * * 32}$ & $-0.022^{* * * * *}$ & -0.002 & $\begin{array}{l}-0.015 \\
(-0.67)\end{array}$ & $\underset{(1.92)}{0.112^{*}}$ \\
\hline $5 \mathrm{PC}$ & $\begin{array}{l}0.00 \\
(0.01)\end{array}$ & $\begin{array}{c}0.02 \text { **** } \\
(3.08)\end{array}$ & $\begin{array}{l}0.03^{*} \\
(1.88)\end{array}$ & $\begin{array}{l}-0.05 \\
(-1.22)\end{array}$ & $\begin{array}{l}-0.02 \\
(-0.16)\end{array}$ \\
\hline 6PC & $\begin{array}{l}0.00 \\
(0.69)\end{array}$ & $\begin{array}{l}0.01 \\
(0.81)\end{array}$ & $\begin{array}{c}0.03^{* * * * *} \\
(49)\end{array}$ & $\begin{array}{l}0.03 \\
(0.65)\end{array}$ & $\begin{array}{l}0.24^{*} \\
(1.91)\end{array}$ \\
\hline 7PC & $\begin{array}{l}0.00 \\
(0.27)\end{array}$ & $\begin{array}{l}-0.00 \\
(-0.28)\end{array}$ & $\begin{array}{l}-0.00 \\
(-0.55)\end{array}$ & $\underset{(-1.70)}{-0.02 *}$ & $-0.10^{*}$ \\
\hline $8 \mathrm{PC}$ & $\begin{array}{l}0.02^{* * 0 * * *} \\
(3.07)\end{array}$ & $\begin{array}{l}0.02 \\
(1.43)\end{array}$ & $\begin{array}{l}-0.01 \\
(-0.74)\end{array}$ & 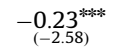 & $\begin{array}{l}-0.17 \\
(-1.56)\end{array}$ \\
\hline Age & $\begin{array}{l}0.00 \\
(0.08)\end{array}$ & -0.00 & $\underset{(1.12)}{0.00}$ & -0.01 & $\begin{array}{l}-0.00 \\
(-0.12)\end{array}$ \\
\hline Amount issued & $-0.025^{\text {****** }}$ & $-{ }_{(-1.34)}^{0.012}$ & $\begin{array}{l}0.032 * * \\
(2.57)\end{array}$ & 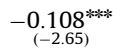 & $-{ }_{(-0.87)}^{0.143}$ \\
\hline Forecast dispersion & $\begin{array}{l}3.05 \\
(1.64)\end{array}$ & $\begin{array}{l}0.02 \\
(1.30)\end{array}$ & $\begin{array}{l}0.73^{* * *} \\
(2.12)\end{array}$ & $\begin{array}{c}0.65^{* * *} \\
(2.04)\end{array}$ & 1.21 \\
\hline Coupon & $0.02^{* * *}$ & $0.02 * * * *$ & $0_{(i .79)}^{0.01^{*}}$ & $\underset{(4.46)}{0.07^{* * * * *}}$ & $0.29 * 2 * * *$ \\
\hline 10y Swap & $-0.05^{*}$ & $-0.03^{* * * * *}$ & $-0.05^{* * * * *}$ & $-0.06^{* * * * *}$ & -0.26 \\
\hline
\end{tabular}


Table B4 (continued)

\begin{tabular}{|c|c|c|c|c|c|}
\hline \multicolumn{6}{|c|}{ Panel A: Pre-subprime (2005:Q1-2007:Q1) } \\
\hline $10 y-1 y$ Swap & $\underset{(0.79)}{0.005}$ & $-\underset{(-2.28)}{0.030 * *}$ & 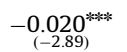 & $-0.107^{* * * *}$ & $\underset{(-0.44)}{-0.132}$ \\
\hline Equity vol & $\underset{(-0.33)}{-0.002}$ & $\begin{array}{c}0.008^{* * * *} \\
(15.21)\end{array}$ & $0_{(1.68)}^{0.006 *}$ & $\underset{(4.17)}{0.011^{* * * *}}$ & $\begin{array}{c}0.093^{* * * * *} \\
(5.88)\end{array}$ \\
\hline Pretax 1 & $\begin{array}{c}0.344^{* * * * *} \\
(3.53)\end{array}$ & $\begin{array}{c}0.023^{* * * * *} \\
(2.88)\end{array}$ & $\begin{array}{c}0.010 \\
(0.57)\end{array}$ & $\underset{(-1.36)}{-0.026}$ & $\begin{array}{c}0.027 \\
(0.44)\end{array}$ \\
\hline Pretax2 & $-\underbrace{0.051^{* * * * *}}_{(-3.06)}$ & $-0.016^{* * * * *}$ & $-\underset{(-1.90)}{0.011^{*}}$ & $\underset{(-1.54)}{-0.013}$ & $\underset{(-0.90)}{-0.068}$ \\
\hline Pretax3 & $\underset{(-1.00)}{-0.007}$ & $\underset{(0.18)}{0.000}$ & $\underset{(-0.35)}{-0.001}$ & $\underbrace{0.011^{* * *}}_{(2.18)}$ & $\begin{array}{c}0.048 \\
(0.95)\end{array}$ \\
\hline Pretax4 & $\begin{array}{c}-0.003^{\text {***** }} \\
(-3.78)\end{array}$ & $\begin{array}{c}0.000 \\
(0.03)\end{array}$ & $\begin{array}{c}0.000 \\
(0.26)\end{array}$ & $-\underset{(-3.31)}{0.005^{* * *}}$ & $\underset{(-1.30)}{-0.022}$ \\
\hline Sales to income & $\underset{(-1.14)}{-0.002}$ & $\underset{(-0.53)}{-0.000}$ & $\underset{(-0.01)}{-0.000}$ & $-\underset{(-2.14)}{0.005^{* *}}$ & $-{ }_{(-1.97)}^{0.003}$ \\
\hline Long term debt to asset & $-\underset{(-2.49)}{0.016^{* *}}$ & $-0.002^{* * * * * *}$ & 0.001 & $\begin{array}{c}0.008^{* * * * *} \\
(2.92)\end{array}$ & $\begin{array}{c}-0.001 \\
(-0.02)\end{array}$ \\
\hline Leverage ratio & $\begin{array}{l}0.009^{* * * * * *} \\
(3.04)\end{array}$ & $\begin{array}{c}0.001 \\
(1.58)\end{array}$ & $\underset{(-1.00)}{0.001}$ & $\begin{array}{c}0.000 \\
(0.10)\end{array}$ & $\begin{array}{c}0.023 \\
(0.91)\end{array}$ \\
\hline Time-to-maturity & ${ }_{(3.50)}^{0.016}$ & $\frac{0.019^{* * * *}}{(18.21)}$ & 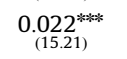 & $0.040^{\text {****** }}$ & $\begin{array}{c}0.043^{* * * * *} \\
(2.99)\end{array}$ \\
\hline$N$ & 533 & 1869 & 4148 & 1340 & 1075 \\
\hline$R^{2}$ & 0.46 & 0.53 & 0.47 & 0.60 & 0.61 \\
\hline \multicolumn{6}{|c|}{ Panel B: Post-subprime (2007:Q2-2009:Q2) } \\
\hline & AAA & $\mathrm{AA}$ & A & BBB & Spec \\
\hline Intercept & $\frac{-2.5^{* *}}{(-2.00)}$ & $\begin{array}{l}-2.6 \\
(-1.00)\end{array}$ & $\begin{array}{c}1.0^{* * * * * *} \\
(2.66)\end{array}$ & $\begin{array}{l}24.9 \\
(1.42)\end{array}$ & $\begin{array}{c}30.2^{*} \\
(1.65)\end{array}$ \\
\hline $1 \mathrm{PC}$ & ${ }_{(1.91)}^{0.05^{*}}$ & $0.48^{* * * * *}$ & $0.45^{* * * * *}$ & $\underbrace{0.67^{* * * *}}_{(3.18)}$ & $1.16^{* * * * * *}$ \\
\hline $2 \mathrm{PC}$ & $\frac{-0.08}{(-0.57)}$ & $\begin{array}{l}0.15 \\
(1.60)\end{array}$ & $0.26^{* * *}$ & $\frac{-0.03}{(-0.05)}$ & -0.73 \\
\hline $3 P C$ & $\underset{(1.21)}{0.066}$ & $\begin{array}{c}0.153^{* * * * *} \\
\end{array}$ & $\begin{array}{c}0.146^{* * * *} \\
(3.27)\end{array}$ & $\underset{(1.75)}{0.389^{*}}$ & $\begin{array}{c}0.349 \\
(0.90)\end{array}$ \\
\hline $4 \mathrm{PC}$ & $\underset{(-1.35)}{0.125}$ & ${ }_{(5.14)}^{0.283^{* * * *}}$ & ${ }_{(4.07)}^{0.267^{* * * *}}$ & $0_{(1.81)}^{0.110^{*}}$ & ${ }_{(1.40)}^{0.900}$ \\
\hline $5 P C$ & $\begin{array}{c}-0.35^{* * * *} \\
(-2.75)\end{array}$ & -0.18 & $-\frac{0.17^{* * * * *}}{(-7.65)}$ & $\frac{-0.46}{(-0.90)}$ & $\begin{array}{l}0.52 \\
(0.97)\end{array}$ \\
\hline $6 P C$ & $\underset{(-1.76)}{0.09 *}$ & $\begin{array}{l}-0.17 \\
(-1.30)\end{array}$ & $\underset{(-1.67)}{-0.41^{*}}$ & $\underset{(-1.70)}{-0.30^{*}}$ & $\begin{array}{c}1.00^{* * *} \\
(2.57)\end{array}$ \\
\hline 7PC & $\begin{array}{l}0.07 \\
(0.68)\end{array}$ & $\underset{(-1.79)}{-0.39 *}$ & -0.22 & -0.44 & $-0.58^{\text {**** }}$ \\
\hline $8 \mathrm{PC}$ & $\underset{(1.72)}{0.12 *}$ & $\begin{array}{l}0.07 \\
(0.30)\end{array}$ & $-0.29 * *$ & $\begin{array}{l}1.04 \\
(1.11)\end{array}$ & $\begin{array}{l}0.63 \\
(0.54)\end{array}$ \\
\hline Age & $-\underset{(-4.83)}{0.03 * * *}$ & -0.02 & $\begin{array}{l}0.02 \\
(0.52)\end{array}$ & $\begin{array}{l}0.10 \\
(1.02)\end{array}$ & $0.18^{* * * *}$ \\
\hline Amount issued & $0_{(4.22)}^{0.087^{* * * *}}$ & $\underset{(1.27)}{0.101}$ & $\begin{array}{c}0.009 \\
(0.09)\end{array}$ & $\underset{(-1.04)}{-0.715}$ & -0.571 \\
\hline Forecast dispersion & $\frac{18.32^{* * * * *}}{(3.07)}$ & $\underbrace{0.13^{* * * *}}_{(3.75)}$ & $\underset{(3.34)}{0.15^{* * * * *}}$ & $\underset{(7.31)}{0.76^{* * * *}}$ & $\underset{(4.31)}{1.06^{* * * *}}$ \\
\hline Coupon & $0.10_{(4.46)}^{* * * *}$ & ${ }_{(2.07)}^{0.10^{* * *}}$ & $\begin{array}{l}0.02 \\
(0.17)\end{array}$ & $\begin{array}{l}-0.50 \\
(-1.34)\end{array}$ & $\begin{array}{l}-0.09 \\
(-0.19)\end{array}$ \\
\hline 10y Swap & $-\underset{(-6.18)}{0.32^{* * * *}}$ & $\begin{array}{l}0.07 \\
(0.24)\end{array}$ & $\frac{-0.09}{(-0.22)}$ & $\begin{array}{c}-1.33^{* * * * *} \\
(-3.25)\end{array}$ & $\begin{array}{c}-3.18^{* * * * *} \\
(-3.05)\end{array}$ \\
\hline 10y-1y Swap & $-{ }_{(-2.17)}^{0.400 * *}$ & $\underset{(-1.58)}{0.490}$ & $\begin{array}{c}-0.820 * \\
(-1.95)\end{array}$ & $\underset{(-1.23)}{-0.962}$ & $-1.962^{* * * *}$ \\
\hline Equity vol & $\underset{(6.22)}{0.096^{* * * *}}$ & $\underbrace{0.055^{* * * *}}_{(3.82)}$ & ${ }_{(3.64)}^{0.050^{* * * * *}}$ & ${ }_{(3.06)}^{0.050^{* * * * *}}$ & $\underset{(3.24)}{0.097^{* * * *}}$ \\
\hline Pretax1 & $-\underset{(-2.17)}{0.836^{* *}}$ & $\begin{array}{c}0.004 \\
(0.21)\end{array}$ & $-{ }_{(-1.80)}^{0.098^{*}}$ & $\underset{(-0.53)}{-0.051}$ & $\begin{array}{c}0.001 \\
(0.44)\end{array}$ \\
\hline Pretax2 & $\begin{array}{l}0.422^{*} * * * * \\
(5.33)\end{array}$ & $\begin{array}{c}0.033 \\
(0.93)\end{array}$ & $\underset{(-0.00)}{-0.000}$ & $\underset{(-0.53)}{-0.073}$ & $\frac{-0.442}{(-0.53)}$ \\
\hline Pretax3 & $\begin{array}{c}0.144 \\
(0.78)\end{array}$ & 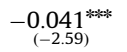 & $\underset{(-0.37)}{-0.003}$ & $\begin{array}{c}0.076 \\
(0.81)\end{array}$ & $\underset{(\mathrm{NaN})}{0.000}$ \\
\hline Pretax4 & $\begin{array}{c}0.003 \\
(0.65)\end{array}$ & $\underset{(1.83)}{0.052^{*}}$ & $\underset{(0.50)}{0.008}$ & $\underset{(-0.62)}{-0.067}$ & ${ }_{(\mathrm{NaN})}^{0.000}$ \\
\hline Sales to income & $-0.108^{*}$ & $-0.003^{* * * * *}$ & $-0.001^{* * * * *}$ & $-\underset{(-7.81)}{0.002^{* * * *}}$ & $\underset{(-1.25)}{-0.013}$ \\
\hline Long term debt to asset & $-0.256^{* * * *}$ & $\begin{array}{c}-0.009 \\
(-0.71)\end{array}$ & $0.044^{* * * *}$ & $\underset{(1.56)}{0.058}$ & $-0.108^{* * * * *}$ \\
\hline Leverage ratio & $\underset{(1.92)}{0.184^{*}}$ & $\begin{array}{c}0.000 \\
(0.00)\end{array}$ & $-0.026^{* * * * *}$ & $\underset{(-0.17)}{-0.005}$ & $\underset{(13.08)}{0.106^{\text {***** }}}$ \\
\hline Time- to-maturity & $\frac{0.024^{* * * * *}}{(6.00)}$ & $\begin{array}{c}-0.015 \\
(-0.96)\end{array}$ & $-0.035^{*}$ & $\underset{(-1.43)}{-0.064}$ & $-0.124^{* * * * *}$ \\
\hline$N$ & 414 & 1549 & 2533 & 539 & 464 \\
\hline$R^{2}$ & 0.84 & 0.71 & 0.67 & 0.79 & 0.72 \\
\hline
\end{tabular}

The table shows that only the first principal component consistently predicts yield spreads, while the remaining seven principal components are mostly insignificant and often with conflicting signs. This suggests that although liquidity has many different aspects, $\lambda$ explains much of the impact of liquidity on yield spreads. 


\section{References}

Acharya, V., Amihud, Y., Bharath, S., 2010. Liquidity risk of corporate bond returns. Unpublished working paper, New York University and University of Michigan.

Acharya, V., Pedersen, L.H., 2005. Asset pricing with liquidity risk. Journal of Financial Economics 77, 375-410.

Amihud, Y., 2002. Illiquidity and stock returns: cross-section and timeseries effects. Journal of Financial Markets 5, 31-56.

Amihud, Y., Mendelson, H., Pedersen, L.H., 2005. Liquidity and asset prices. Foundations and Trends in Finance 1, 269-364.

Aragon, G.O., Strahan, P.E. Hedge funds as liquidity providers: evidence from the Lehman bankruptcy. Journal of Financial Economics, doi:10. 1016/j.jfineco.2011.10.004. In press.

Bao, J., Pan, J., Wang, J., 2011. The illiquidity of corporate bonds. Journal of Finance 66, 911-946.

Bessembinder, H., Maxwell, W., Venkaraman, K., 2006. Market transparency, liquidity externalities, and institutional trading costs in corporate bonds. Journal of Financial Economics 82, 251-288.

Blanco, R., Brennan, S., Marsh, I.W., 2005. An empirical analysis of the dynamic relationship between investment grade bonds and credit default swaps. Journal of Finance 60, 2255-2281.

Blume, M.E., Lim, F., MacKinlay, A.C., 1998. The declining credit quality of U.S. corporate debt: Myth or reality? Journal of Finance 53 1389-1401

Bongaerts, D., Driessen, J., de Jong, F., 2011. Derivative pricing with liquidity risk: theory and evidence from the credit default swap market. Journal of Finance 66, 203-240.

Brunnermeier, M., Pedersen, L.H., 2009. Market liquidity and funding liquidity. Review of Financial Studies 22, 2201-2238.

Cameron, C., Gelbach, J., Miller, D., 2008. Bootstrap-based improvements for inference with clustered errors. Review of Economic Studies 90, 414-427.

Chen, L., Lesmond, D., Wei, J., 2007. Corporate yield spreads and bond liquidity. Journal of Finance 62, 119-149.

Collin-Dufresne, P., Goldstein, R.S., Martin, J., 2001. The determinants of credit spread changes. Journal of Finance 56, 2177-2207.

Comerton-Forde, C., Hendershott, T., Jones, C.M., Moulton, P.C., Seasholes, M.S., 2010. Time variation in liquidity: the role of marketmaker inventories and revenues. Journal of Finance 65, 295-332.

Covitz, D., Downing, C., 2007. Liquidity or credit risk? The determinants of very short-term corporate yield spreads. Journal of Finance 62, 2303-2328.

Davidson, R., MacKinnon, J.G., 1993. Estimation and Inference in Econometrics. Oxford University Press, New York.

de Jong, F., Driessen, J., 2006. Liquidity risk premia in corporate bond markets. Unpublished working paper, Tilburg University and University of Amsterdam.

Dick-Nielsen, J., 2009. Liquidity biases in TRACE. Journal of Fixed Income $19,43-55$.

Downing, C., Underwood, S., Xing, Y., 2005. Is liquidity risk priced in the corporate bond market? Unpublished working paper, Rice University.

Duffie, D., Lando, D., 2001. Term structures of credit spreads with incomplete accounting information. Econometrica 69, 633-664.

Edwards, A.K., Harris, L.E., Piwowar, M.S., 2007. Corporate bond market transaction cost and transparency. Journal of Finance 62, 1421-1451.
Ellis, K., Michaely, R., O'Hara, M., 2000. When the underwriter is the market maker: an examination of trading in the IPO aftermarket. Journal of Finance 55, 1039-1074.

Elton, E., Gruber, M., Agrawal, D., Mann, C., 2001. Explaining the rate spread on corporate bonds. Journal of Finance 56, 247-277.

Ericsson, J., Renault, O., 2006. Liquidity and credit risk. Journal of Finance 61, 2219-2250.

Feldhütter, P. The same bond at different prices: identifying search frictions and selling pressures. The Review of Financial Studies, doi:10.1093/rfs/hhr093. In press.

Feldhütter, P., Lando, D., 2008. Decomposing swap spreads. Journal of Financial Economics 88, 375-405.

Friewald, N., Jankowitsch, R., Subrahmanyam, M.G. Illiquidity or credit deterioration: a study of liquidity in the US corporate bond market during financial crises. Journal of Financial Economics, forthcoming

Güntay, L., Hackbarth, D., 2010. Corporate bond credit spreads and forecast dispersion. Journal of Banking and Finance 34, 2328-2345.

Goldstein, M.A., Hotchkiss, E., 2008. Dealer behavior and the trading of newly issued corporate bonds. Unpublished working paper, Boston College.

Goldstein, M.A., Hotchkiss, E., Sirri, E.R., 2007. Transparency and liquidity: a controlled experiment on corporate bonds. The Review of Financial Studies 20, 235-273.

Han, S., Zhou, H., 2008. Effects of bond liquidity on the nondefault component of corporate bond spreads: evidence from intraday transactions data. Unpublished working paper, Federal Reserve Board.

Houweling, P., Mentink, A., Vorst, T., 2005. Comparing possible proxies of corporate bond liquidity. Journal of Banking and Finance 29, 1331-1358.

Huang, J., Huang, M., 2003. How much of the corporate-treasury yield spread is due to credit risk? Unpublished working paper, Penn State University and Stanford University.

Huberman, G., Stanzl, W., 2005. Optimal liquidity trading. Review of Finance 9, 165-200.

Hull, J., Predescu, M., White, A., 2004. The relationship between credit default swap spreads, bond yields, and credit rating announcements. Journal of Banking and Finance 28, 2789-2811.

Korajczyk, R., Sadka, R., 2008. Pricing the commonality across alternative measures of liquidity. Journal of Financial Economics 87, 45-72.

Kyle, A.S., 1985. Continuous auctions and insider trading. Econometrica 53, 1315-1334.

Lin, H., Wang, J., Wu, C., 2011. Liquidity risk and expected corporate bond returns. Journal of Financial Economics 99, 628-650.

Longstaff, F., Mithal, S., Neis, E., 2005. Corporate yield spreads: default risk or liquidity? New evidence from the credit-default swap market. Journal of Finance 60, 2213-2253.

Mahanti, S., Nashikkar, A., Subramanyam, M.G., Chacko, G., Mallik, G., 2008. Latent liquidity: a new measure of liquidity with an application to corporate bonds. Journal of Financial Economics 88, 272-298.

Petersen, M.A., 2009. Estimating standard errors in finance panel data sets: comparing approaches. Review of Financial Studies 22, 435-480.

Roll, R., 1984. A simple implicit measure of the effective bid-ask spread in an efficient market. Journal of Finance 39, 1127-1139.

Sarig, O., Warga, A., 1989. Bond price data and bond market liquidity. Journal of Financial and Quantitative Analysis 24 (3), 367-378. 